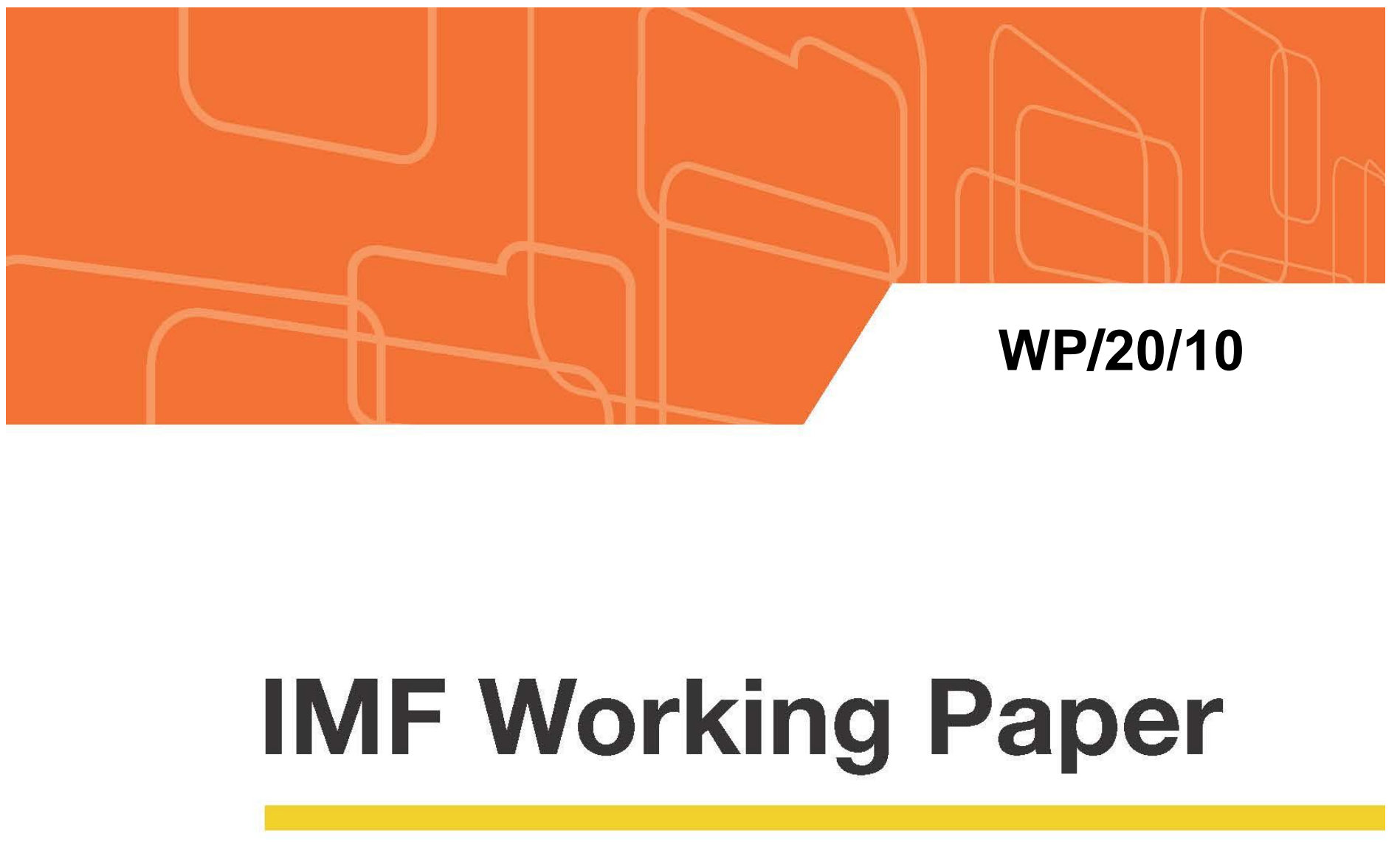

\title{
One Shock, Many Policy Responses
}

by Rui C. Mano and Silvia Sgherri

IMF Working Papers describe research in progress by the author(s) and are published to elicit comments and to encourage debate. The views expressed in IMF Working Papers are those of the author(s) and do not necessarily represent the views of the IMF, its Executive Board, or IMF management. 


\title{
IMF Working Paper
}

Strategy, Policy and Review Department

\section{One Shock, Many Policy Responses}

Prepared by Rui C. Mano and Silvia Sgherri ${ }^{1}$

Authorized for distribution by Rupa Duttagupta and Martin Kaufman

January 2020

\section{IMF Working Papers describe research in progress by the author(s) and are published to elicit comments and to encourage debate. The views expressed in IMF Working Papers are those of the author(s) and do not necessarily represent the views of the IMF, its Executive Board, or IMF management.}

\begin{abstract}
Policymakers have relied on a wide range of policy tools to cope with capital flow shocks. And yet, the effects and interaction of these policies remain under debate, as does the motivation for using them. In this paper, quantile local projections are used to estimate the entire distribution of future policy responses to portfolio flow shocks for 20 emerging markets and understand the variety of policy choices across the sample. To assuage endogeneity concerns, estimates rely on the fact that global capital flows are exogenous from the viewpoint of any one of these countries. The paper finds that: (i) policy responses to capital flow shocks are heterogeneous across countries, fat-tailed- "extreme" responses tend to be more elastic than "typical" responses - and asymmetric - "extreme" responses tend to be more elastic with respect to outflows than to inflows; (ii) country characteristics are linked to policy choices - with cross-country differences in forex intervention relating to the size of balance sheet vulnerabilities and the depth of the forex market; (iii) the use of targeted macroprudential policy and capital flows management measures can help "free the hands" of monetary policy by allowing it to focus more squarely on domestic cyclical developments.
\end{abstract}

JEL Classification Numbers: F32, F38, E52, G28.

Keywords: Capital flows, emerging markets, foreign exchange intervention, macroprudential policies, capital flows management.

Author's E-Mail Address: rmano@imf.org, $\underline{\text { ssgherri@imf.org. }}$

\footnotetext{
${ }^{1}$ International Monetary Fund. We thank Suman S. Basu, Emine Boz, Tam Bayoumi, Marcos Chamon, Rupa Duttagupta, Martin Kaufman, Vladimir Klyuev, participants at the IBRN-IMF workshop on "Policy Interactions and International Spillovers in the Global Economy," and participants in various IMF seminars for their helpful suggestions. Yuting Shao provided excellent research assistance. Remaining errors are our sole responsibility.
} 


\section{INTRODUCTION}

Policymakers in Emerging Markets (EMs) face increasing challenges in managing large and volatile capital flows that are often driven by external factors - particularly in the face of deepening macro-financial linkages and spillovers. Capital inflows into these countries can be extremely beneficial, as they loosen financing constraints, boost the capital stock of the economy, and often improve total factor productivity by bringing new expertise. ${ }^{2}$ However, these inflows can also be very destabilizing, fueling the buildup of financial vulnerabilities and medium-term risks of sudden reversals and asset price busts. ${ }^{3}$ The fact that capital flows present such a stark double-edged sword makes it essential to manage their fickleness effectively.

Interestingly, there is a striking variety of policy responses across countries to episodes of capital flow pressures. Some EMs subscribe to the classical Mundell-Fleming prescription. They allow their exchange rate to be flexible and act as the "first line of defense" against external shocks, while refraining from intervening in forex markets except under extraordinary circumstances. They tend to pursue a "clean" inflation-targeting monetary policy framework, whereby interest rate decisions are guided by expected changes in inflationary pressures and domestic cyclical conditions. This group of countries often uses macroprudential policy measures to target the domestic financial cycle to lean against the buildup of systemic risk. On the other side of the spectrum, other EMs (and some small, open advanced economies) intervene heavily in the forex market to smooth "excessive" exchange rate volatility that they fear is disruptive from a financial stability viewpoint. ${ }^{4}$ They tend to pursue a "flexible" inflation-targeting regime wherein interest rate decisions also respond to exchange rate pressures and growing financial risks, with an eye on shifting relative returns to capital and influence carry traders' incentives. ${ }^{5}$ This group of countries may at times resort to capital flow management measures to affect the composition of flows and foreign currency risk-taking, beyond also relying on macroprudential policies to stem the buildup of external balance sheet vulnerabilities.

To further illustrate this point, consider the recent bout of portfolio outflows hitting EMs in mid-2018. Focusing on forex intervention (FXI), interest rate and exchange rate changes (red, green, and blue bars), the top chart of Figure 1 shows the wide variety-both qualitatively and quantitatively_ of policy responses across a representative sample of 20 EMs. At the same time, the top chart also highlights the important related fact that country-

\footnotetext{
${ }^{2}$ Harrison et al. (2004), Tong and Wei (2011), Ahmed and Zlate (2014) and Igan et al. (2016).

${ }^{3}$ Calvo (2012), Gourinchas and Obstfeld (2012), Furceri et al. (2012).

${ }^{4}$ Calvo and Reinhart (2002) provide evidence of widespread "fear of floating". The wide range of policymakers' views regarding forex intervention is well documented in Neely (2008) and Mohanty and Berger (2013). For a review of the empirical literature on forex interventions in EMs, see Menkhoff (2013).

${ }^{5}$ For recent analyses of the evolution of EMs' monetary policy frameworks and underlying challenges see, among others, BIS (2019a and 2019b) and Fraga et al. (2004).
} 
specific portfolio outflows were also highly heterogeneous across the sample (yellow dots). ${ }^{6}$ To complete the picture, the bottom chart offers a glimpse of the extent to which-over the same period - several EMs also relied on complementary policy tools such as macroprudential measures (MPMs) and capital flow management (CFMs) measures to cope with the undesired effects of capital flow volatility.

Figure 1. Cross-Country Heterogeneity of Policy Responses to Capital Flow Pressures Policy Reactions to A Capital Outflow Episode

(April 1st-September 30th, 2018)

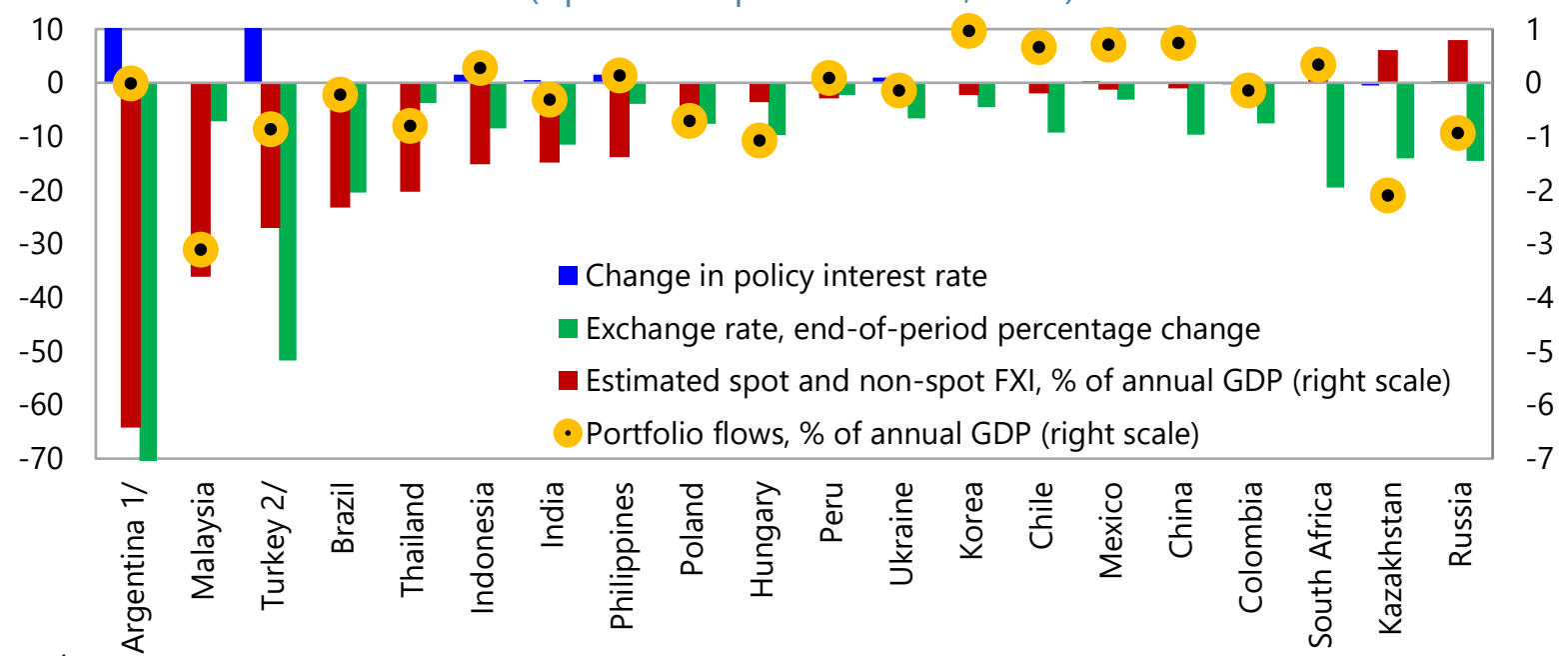

$1 /$ Depreciation $=99.8$ percent; Change in policy rate $=37.75$ percent.

$2 /$ Change in policy rate $=16$ percent.

Sources: COFER, Haver, IRFCL, IFS, WEO, and IMF's staff calculations.

Number of Macroprudential Policy and Capital Flow Management Measures Taken

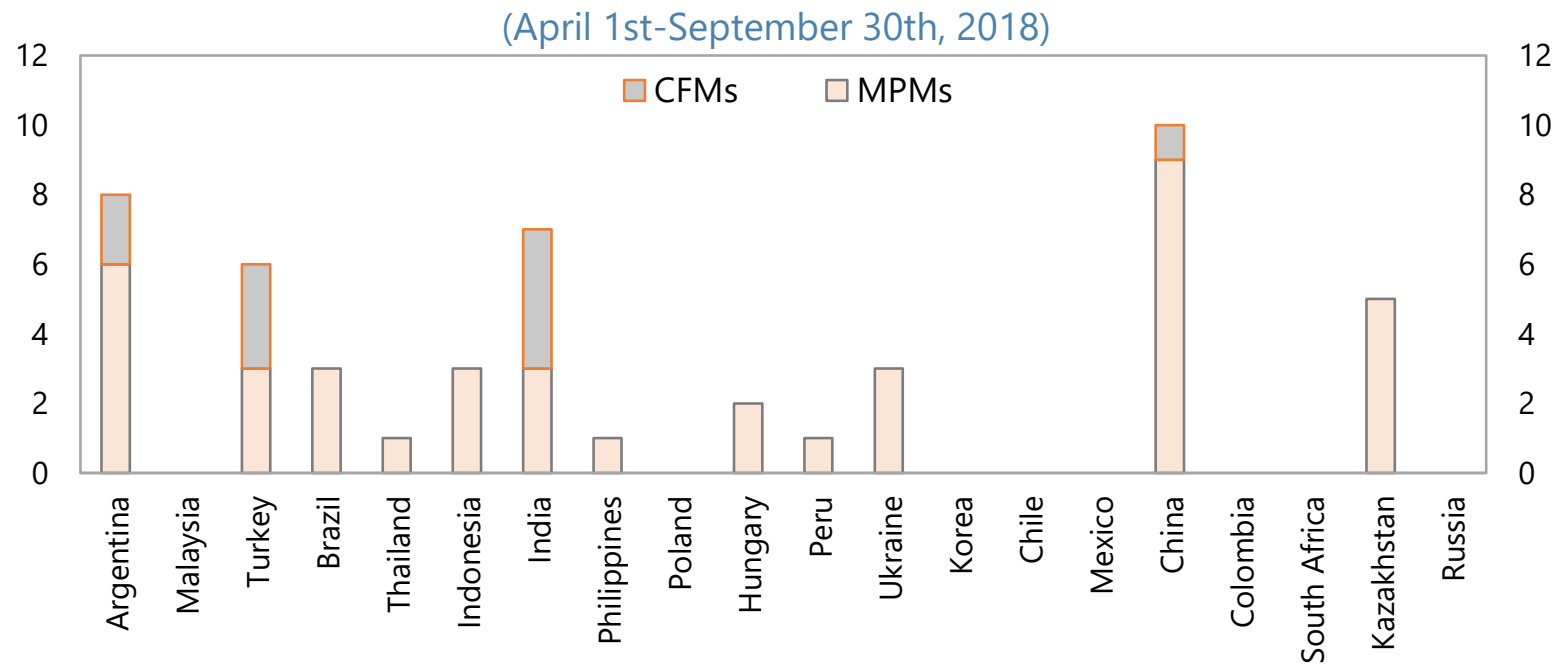

Sources: IMF's Macroprudential Policy Survey database, IMF's Taxonomy of Capital Flow Management Measures, and IMF's staff calculations.

${ }^{6}$ Focusing on the cross-country heterogeneity of portfolio outflows vis-à-vis a common, global shock, Gelos et al. (forthcoming) use a quantile regression framework to predict the probability distribution of future portfolio inflows into EMs, based on current domestic structural characteristics, policies, and global financial conditions. 
Existing research, so far, does not provide guidance on how to assess the choice of a country's policy mix in the face of exogenous capital flow pressures, as the effects of many of these policies - let alone their interaction - remain under debate among both academics and policy practitioners.

In this paper, we document such a variety of policy responses to external capital flow pressures for a representative sample of EMs over a sufficiently long period and investigate the rationale behind them. Specifically, the paper poses three related questions:

1) Focusing on FXI, interest rate and exchange rate changes, what determines the likelihood of (and risks to) a given country's policy move tomorrow in response to an exogenous inflow of capital today? Can we predict changes in such a policy response (and corresponding risks) over time?

2) Is the wide cross-country heterogeneity of these policy responses somehow related to structural country-specific characteristics?

3) How does the use of complementary policy tools - such as MPMs and CFMsinteract with the policy responses under consideration?

To tackle these questions, we rely on quantile local projections (Jordà, 2005) at individual country level. This allows to predict — for each EM in the sample and at each point in timethe entire probability distribution of future country-specific policy responses to global portfolio flow shocks at various horizons, conditional upon prevailing global and domestic macro-financial conditions. To assuage endogeneity concerns, the analysis relies on the fact that global portfolio flows are exogenous from the viewpoint of any one of the emerging markets in our sample - thereby making it possible to focus strictly on differences in policy responses while abstracting from differences in idiosyncratic country-specific flows. ${ }^{7} \mathrm{We}$ then use predictions across a range of quantiles to generate the conditional empirical distribution of future FXI, interest rate and exchange rate responses to (essentially) the samesized external portfolio flow shock, and fit them to skewed-t probability distributions to facilitate a quantitative risk assessment of the estimated policy responses.

The use of a quantile regression approach is motivated by the fact that, in reality, policy responses in many countries tend to be heteroskedastic - with "typical" and "extreme" responses possibly reflecting different driving forces. As exemplified in Figure 2, by looking at the history of FXI or interest rate changes in selected countries, one often observes that the unconditional distribution of these policy responses tends to be fat-tailed-featuring several episodes of extreme policy actions (left chart) — and asymmetric - with more intense actions at one end of the distribution than at the other end (right chart).

\footnotetext{
${ }^{7}$ On this point, see Blanchard et al. (2015).
} 
Figure 2. Fat-tailness and Asymmetry in the (Unconditional) Distribution of Selected Country-Level Policy Actions, 2000Q1-2018Q3
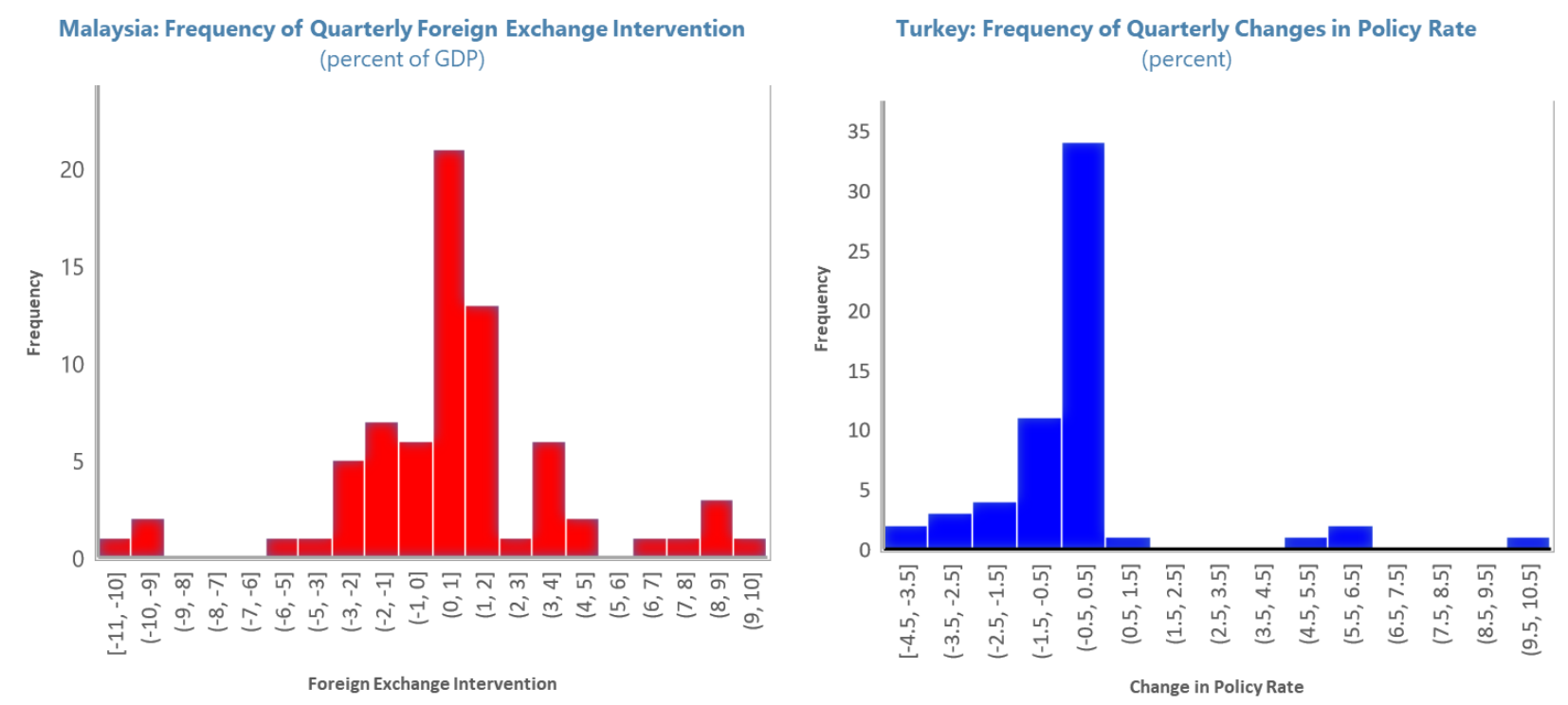

Sources: WEO, IFS and IMF staff estimates.

The framework proposed in this paper represents in itself a contribution to both the policymaking debate and the surveillance of countries' policies. From a bilateral surveillance perspective, the framework helps assess the likelihood that - under certain domestic and global macro-financial conditions - a given country will deploy a given policy move tomorrow in response to a global portfolio flow shock hitting the economy today; it also allows to predict how such a likelihood is likely to shift over time-as the shock wanes or intensifies, and/or as domestic and global macro-financial conditions change. At the same time, the tool can be extremely helpful for multilateral surveillance purposes, as it facilitates a more systematic understanding of observed cross-country differences in the choice of policy mixes vis-à-vis capital flows shocks.

Responding to the paper's key questions outlined above, our empirical findings suggest that:

1) Policy responses to capital flow shocks are highly heterogeneous across countries even after controlling for an exogenous, same-sized shock. Moreover, in most countries, policy responses appear to be fat-tailed, with larger "extreme" responses compared to those around the median, or "typical" responses. Policy responses are also asymmetric, with larger exchange rate adjustment, interest rate changes and FXI in response to outflows than in response to inflows.

2) Different policy choices across countries can be linked to some country-specific concerns. For example, estimated responses of FXI (both "typical" and "extreme") seem related to balance sheet vulnerabilities and the depth of the forex market. While no causality relationship can be ascertained, we think this analysis contributes to narrowing the list of structural country characteristics that may either explain why certain countries respond a 
certain way or indicate that certain policies, if repeated often, may lead to the development of certain characteristics over time.

3) The use of additional policy measures targeting the buildup of external balance sheet vulnerabilities in the system can help "free the hands" of monetary policy: bringing these policy tools into play appears to strengthen the sensitivity of both "typical" and "extreme" monetary policy responses to expected domestic cyclical developments. The effects of deploying such policies are asymmetric, when looking at forex interventions and exchange rates, and are more prominent at longer horizons.

Our intention is to conduct a purely positive analysis. The paper will not explore countries' optimal policy mix in the face of external shocks. In particular, there could be unexplored longer-term, unintended consequences from the use of these tools that may give rise to important intertemporal policy trade-offs. Similarly, countries may use unconventional policy tools to delay warranted macro-economic adjustment, which could be suboptimal. These important considerations are beyond the scope of this paper.

The rest of the paper proceeds as follows. We first present the empirical methodology and discuss the identification of the shock in Section II. Next, we show how this framework can be used to evaluate policy responses at individual country level in real time (Section III). Model predictions are then employed in Section IV to investigate the link between policy responses and structural country-specific characteristics, and in Section V to explore the interactions of MPMs and CFMs with other policies. Some policy-relevant conclusions are drawn in Section VI.

\section{Methodology}

\section{A. Empirical Framework}

To predict the likelihood of - and risks to-future policy responses in the face of an exogenous capital flow shock and conditional on prevailing global financial conditions and domestic factors, we use quantile regressions at individual country level. ${ }^{8}$ The empirical framework is similar in spirit to the one used for the Growth-at-Risk analysis (Adrian et al., 2019 and 2018; Prasad et al., 2019; Lafarguette, 2019; see also IMF, 2017 and 2018).

To briefly sum up the estimation strategy, let $y_{\mathrm{t}+\mathrm{h}}$ denote a future policy response implemented at time $t+h$, while $x_{\mathrm{t}}$ is a vector of independent variables observed at time $t$. In a quantile regression of $y_{\mathrm{t}+\mathrm{h}}$ on $x_{\mathrm{t}}$, the regression, slope $\beta^{\alpha}$ is chosen to minimize the quantile weighted absolute value of errors such that:

$$
\hat{\beta}^{\alpha}=\arg \min \sum_{t=1}^{T-h}\left(\alpha \cdot 1_{y_{t+h}>x_{t} \beta}\left|y_{t+h}-x_{t} \beta\right|+(1-\alpha) .1_{y_{t+h} \leq x_{t} \beta}\left|y_{t+h}-x_{t} \beta\right|\right)
$$

\footnotetext{
${ }^{8}$ Following Ghosh, Ostry, and Qureshi (2017), IMF (2019) also estimates policy reaction functions for 13 Asian and Pacific countries using OLS, 2SLS, and probit panel estimators.
} 
where $1_{(\cdot)}$ denotes the indicator function and $\alpha$ is the probability value of interest. The predicted value from that regression is the quantile of $y_{t+h}$ conditional on the vector of variables $x_{t}$ :

$$
\hat{\mathbf{Q}}_{y_{t+h} \mid x_{t}}(\alpha)=x_{t} \hat{\beta}^{\alpha}
$$

In our analysis, we consider the following parsimonious model specification where coefficients are estimated as in equation (1):

$$
\begin{aligned}
& \left(\overline{\frac{F X I}{Y^{*}}}\right)_{t+h}^{\alpha}=\beta_{x, f x}^{\alpha} \text { Controls }_{t}+\beta_{s, f x}^{\alpha} \text { Shock }_{t}+\beta_{s p, f x}^{\alpha} \text { Shock }_{t} \times \text { AddPolicy }_{t}+\varepsilon_{f x, t+h}^{\alpha} \\
& (\overline{\Delta i})_{t+h}^{\alpha}=\beta_{x, i}^{\alpha} \text { Controls }_{t}+\beta_{s, i}^{\alpha} \text { Shock }_{t}+\beta_{s p, i}^{\alpha} \text { Shock }_{t} \times \text { AddPolicy }_{t}+\varepsilon_{i, t+h}^{\alpha} \\
& \left(\overline{\frac{\Delta e}{e}}\right)_{t+h}^{\alpha}=\beta_{x, e}^{\alpha} \text { Controls }_{t}+\beta_{s, e}^{\alpha} \text { Shock }_{t}+\beta_{s p, e}^{\alpha} \text { Shock }_{t} \times \text { AddPolicy }_{t}+\varepsilon_{e, t+h}^{\alpha}
\end{aligned}
$$

which represents a mapping between a set of future policy responses (left-hand side variables) and a set of exogenous and/or predetermined regressors (right-hand side variables) across major percentiles $(\alpha)$ and over horizons up to 2 years $(h=1,2,3, \ldots, 8$ quarters). Future policy responses are averaged $\overline{(\cdot)}$ across all preceding horizons whenever looking beyond the first quarter ahead, to facilitate the interpretation of the estimated coefficients.

For expositional purposes, we distinguish between median predictions, on the one hand, and predictions for the $10^{\text {th }}$ and $90^{\text {th }}$ percentiles, on the other hand. The former is henceforth referred to as "typical" responses, while we will refer to the latter as "extreme" responses. Hence, a generally defined extreme policy response $h$ quarter ahead, $E P R_{h}$, is identified by:

$$
\operatorname{Pr}\left(y_{t+h} \leq E P R_{h}\left(\alpha \mid \Omega_{t}\right)\right)<\alpha^{L} \quad \text { or } \quad \operatorname{Pr}\left(y_{t+h} \geq E P R_{h}\left(\alpha \mid \Omega_{t}\right)\right)>\alpha^{H}
$$

where $\operatorname{EPR}_{h}\left(\alpha \mid \Omega_{t}\right)$ captures extreme policy responses $h$ quarters in the future at a $\alpha$ probability. For a low value of $\alpha, E P R_{h}$ captures the expected policy response at the lower end of the distribution. For a high value of $\alpha, E P R_{h}$ captures the expected policy response at the higher end of the distribution.

The set of future policy responses that we explore includes: (i) percentage changes in effective nominal exchange rate; ${ }^{9}$ (ii) foreign exchange intervention, measured in percent of a

\footnotetext{
${ }^{9}$ For robustness, we also estimate bilateral exchange rate responses vis-à-vis the USD. See Annex III.A for related discussion.
} 
given country's own trend GDP; and (iii) changes in the policy rate, in percentage points. To facilitate comparison across countries and interpretation of results, we purposely choose a parsimonious, one-size-fits-all model specification. Nonetheless, nothing precludes further tailoring to better capture country specificities. The key variable of interest is an exogenous measure of external capital flow pressures (Shock), whose definition is discussed in detail in the next sub-section. The set of controls (Controls) that we consider include both exogenous global financial conditions (such as fluctuations in international commodity prices) and predetermined country-specific "pull" factors, such as lagged balance sheet vulnerability indicators (for example, the ratio of short-term foreign currency debt to FX reserves) and lagged macro-financial conditions (such as domestic GDP growth). ${ }^{10}$

We also assess the complementarity role of additional policy tools (AddPolicy) — such as MPMs or CFMs - in order to explore their tendency to mitigate or amplify the relevant policy response in the face of exogenous capital flow pressures. This is done by interacting the shock (Shock) with such additional policy instruments (AddPolicy) in each of the 3 equations and for each country of interest, while also including this additional policy variable as a stand-alone control in each of the regressions. AddPolicy is a constructed variable that takes a value 0 if no policy change is implemented, a value +1 if there is a tightening (easing) in MPMs or CFMs on inflows (outflows), and a value -1 if there is an easing (tightening) in MPMs or CFMs on inflows (outflows). Subsection C. below discusses more extensively definitions and data underlying the construction of these interaction terms.

The analysis is based on quarterly data from 1996Q3 to 2018Q3 for the 20 EMs reported in Figure $1 .{ }^{11}$ Annex II.A provides a list of countries and relevant data description. Annex I reports the estimated sensitivity to the shock of each future policy response considered - that is, $\hat{\beta}_{s, f x}^{\alpha} \hat{\beta}_{s, i}^{\alpha}$ and $\hat{\beta}_{s, e}^{\alpha}$ _ for each EM and for different percentiles of the distribution, jointly with corresponding estimates of the separate (mitigating or amplifying) impact of complementary policy tools - namely, $\hat{\beta}_{s p, f x}^{\alpha} \hat{\beta}_{s p, i}^{\alpha}$ and $\hat{\beta}_{s p, e}^{\alpha} \cdot{ }^{12}$ To highlight different shortterm and medium-term sensitivities, estimates in Annex I, Table 1 capture future average responses over the next two quarters $(h=2)$, while estimates in Annex I, Table 2 reflect future average responses over the next two years $(h=8)$.

After having estimated the empirical distributions of future policy responses based on the empirical percentiles from the regressions, we follow Adrian et al (2018) in fitting the empirical distribution to a theoretical skewed-t probability distribution. This is done by minimizing the sum of squared residuals between the empirical percentile functions and the

\footnotetext{
${ }^{10}$ Given limited time variation of domestic structural conditions when working with country-level data, we only control for the impact of domestic cyclical conditions on future policy responses. To lessen endogeneity concerns when assessing the role of these cyclical macro-financial factors on future policy moves, we use information up to the previous (rather than current) quarter.

${ }^{11}$ To warrant adequate power to the estimates, policy response functions are estimated over the full sample without attempting to identify possible shifts in countries' policy frameworks over this period.

${ }^{12}$ For the sake of brevity, estimated impact of the global and domestic controls on the responses have not been reported in the Tables 1 and 2, but are available upon request.
} 
skewed-t distribution, which is characterized by four moments (e.g., mean, variance, skewness, and kurtosis) and flexibly nests both normal and standard t-distribution (Azzalini and Capitanio, 2003). For each of the 20 emerging markets in the sample, such conditional forecast distributions allow us to quantify the likelihood and risks associated with any future policy response estimated at each point in time and over a given horizon, while staying broadly agnostic about the exact shape of the distribution of such responses. As exemplified in Section III, this approach makes possible a quantitative risk assessment of countries' policy responses over time.

\section{B. The Shock}

From an empirical perspective, a key challenge in estimating the sensitivity of policy responses to a capital flow shock is that policy actions may themselves affect foreign investors decisions and thereby induce changes in portfolio flows to the country. This may introduce an endogeneity bias in the estimated coefficients $\beta_{s,}^{\alpha}$ and $\beta_{s p,}^{\alpha}$, in equation (2) which, if unaddressed, would not allow the identification of the policy response to the shock.

To assuage this concern, we construct a plausibly exogenous global capital flow shock following Blanchard et al. (2015). For each country $j$, our exogenous measure of aggregate gross portfolio flows is constructed as the sum of gross private portfolio inflows to all other countries in our sample, leaving out country $j .{ }^{13}$ We then scale the aggregate shock by the rolling 4-quarter sum of quarterly nominal HP-filtered GDP (in US dollars) of all other countries. By smoothing the denominator, we ensure that any high frequency variation in the shock reflects corresponding movements in global portfolio inflows rather than business cycle volatility. Given the relatively small share of portfolio inflows allocated to any given country, this shock can be roughly thought of as a common global portfolio flow shock.

Figure 3 shows the constructed capital flow shock for each of the 20 emerging markets in our sample. As indicated, each country-specific shock is close to identical across countries, reflecting each country's small marginal contribution to aggregate flows into/out of the whole group. Importantly, this set of country-specific shocks is found to be highly (and inversely) correlated with the VIX - a clear indication that they essentially reflect push factors and proxy shifts in global risk aversion and/or fundamental uncertainty.

\footnotetext{
${ }^{13}$ We focus on gross portfolio inflows rather than total inflows as portfolio investments typically have a shorter investment horizon and are more sensitive to shifts in global risk-aversion. We look at gross rather than net inflows, as dynamics in net inflows cannot be solely attributed to changes in foreign investors' behavior (Forbes and Warnock, 2012).
} 
Figure 3. Constructing an Exogenous Portfolio Flow Shock for Each Country

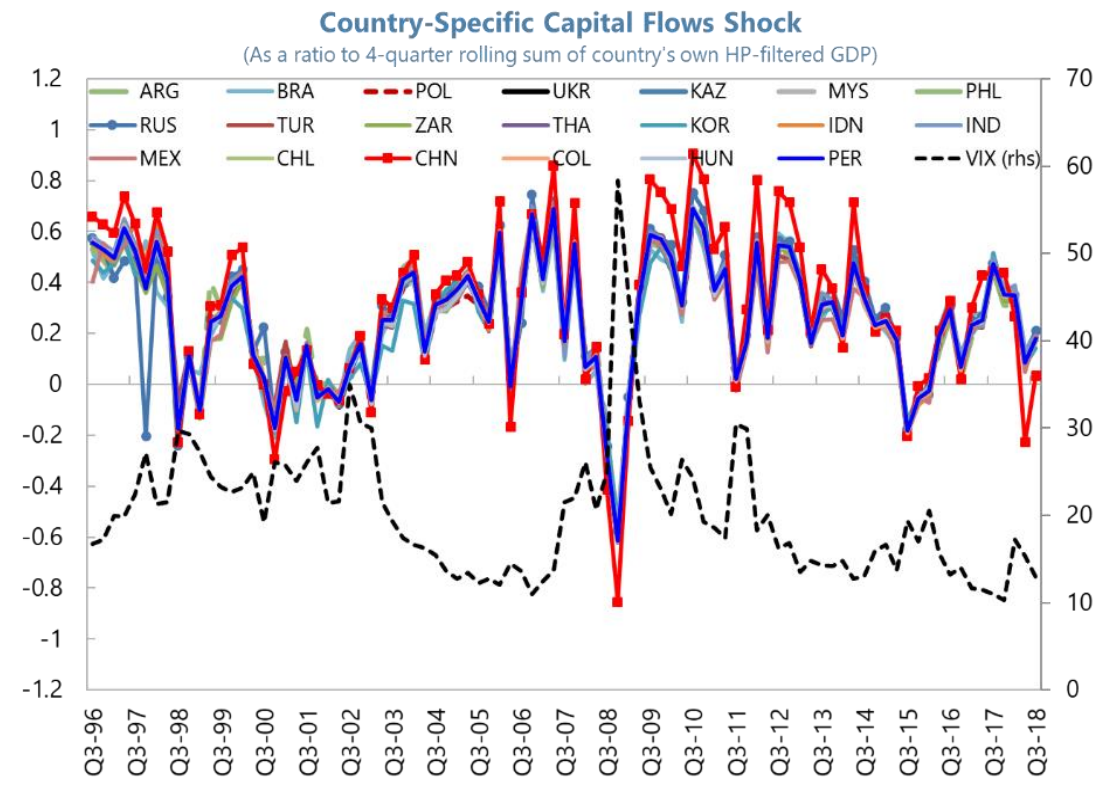

Sources: WEO, IMF staff estimates.

\section{Accounting for the Role of Additional Policy Tools}

Following the Global Financial Crisis, researchers and policymakers have looked closely at the use of unconventional policy tools - such as MPMs and CFMs - aimed at curbing the buildup of external vulnerabilities in the system and affecting the composition of foreign currency risk-taking. ${ }^{14}$ An important limitation to the evaluation of these policy tools, thus far, has been the lack of cross-country measures of their intensive margins (i.e. rates). Ideally, a researcher would need to have not only information on their extensive margins - i.e. whether a measure was introduced, tightened or eased-but also a sense of the magnitude or intensity of such measure to consider its effects. ${ }^{15}$

Unfortunately, there is no comprehensive dataset that measures the intensity of MPMs or CFMs. ${ }^{16}$ We thus need to turn to data reporting the number and direction of policy actions for each quarter. For this purpose, we use two sources of data: (1) the IMF's Macroprudential Policy Survey database ( $M a P P$ ) - a newly constructed dataset on MPMs described in Alam et al. (2019); and (2) the IMF's 2019 Taxonomy of Capital Flow Management Measures (the Taxonomy).

\footnotetext{
${ }^{14}$ Bianchi (2011); Jeanne and Korinek (2019); Korinek (2018); Korinek and Sandri (2016).

${ }^{15}$ A parallel to this problem in the world of taxation is that the researcher doesn't know the change in a given tax rate let alone the tax base, and instead only knows that the tax rate was increased.

${ }^{16}$ Using textual analysis, Acosta-Henao et al. (forthcoming) construct a cross-country panel dataset on the extensive and intensive margin for two types of quantitative capital controls: unremunerated reserve requirement rates applicable to cross-border inflows; and tax rates to cross-border inflows and outflows.
} 
The $i M a P P$ dataset includes data on a wide range of MPMs. ${ }^{17}$ However, many of them are not as relevant for either the type of country or the type of shocks we are interested in. Figure 4 illustrates this perspective by showing the prevalence of different types of instruments across Advanced Economies (AEs) and Emerging Markers and Developing Economies (EMDEs), respectively. While MPMs targeting forex (FX) positions are the least popular macroprudential tool among AEs, they appear to be the most widely used tools among EMDEs. This clearly reflects different concerns (and risks) in the two types of economies: on average, EMDEs tend to be more exposed than AEs to vulnerabilities from external shocks and the potential systemic risks triggered by sharp changes in the exchange rate.

Figure 4: The Prevalence of MPMs Across AEs and EMDEs
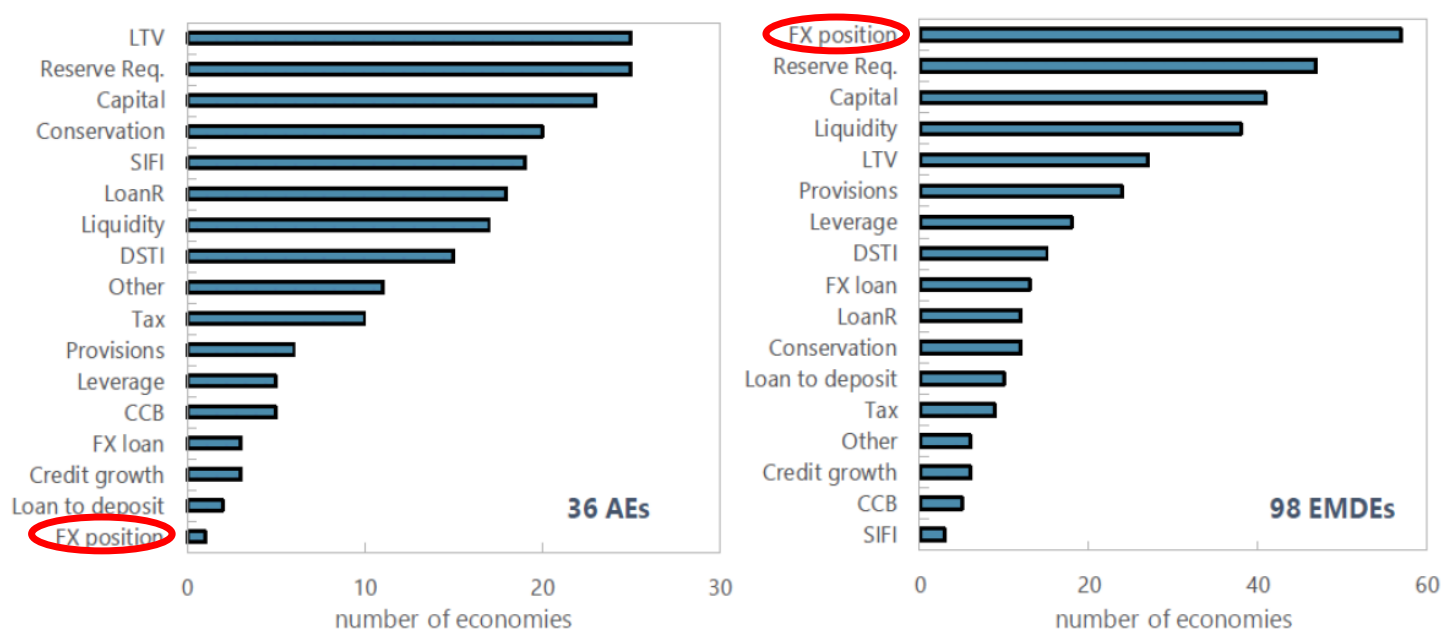

Sources: Alam and others (2019).

Notes: The chart shows the number of economies in which MPMs were introduced by type of MPM. It thus shows the scope of such measures across countries within the group of Advanced Economies (AEs) and Emerging and Developing Economies (EMDEs).

In this paper, we specifically focus on MPMs that target FX positions either explicitly or implicitly, such as: (1) Reserve requirements imposed for macroprudential purposes - that is to mitigate systemic risks - either differentiated by currencies or differentiated by residency; (2) Limits on net or gross open FX positions, (3) limits on FX exposures, FX funding, and currency mismatch regulations; (4) Limits on foreign currency (FC) lending, and rules or recommendations on FC loans.

The Taxonomy serves as a reference for the various types of measures that have been taken by countries to manage and liberalize capital flows. It contains information about measures assessed by Fund staff as CFMs and discussed in published IMF staff reports since the adoption of the Institutional View on the Liberalization and Management of Capital Flows

\footnotetext{
${ }^{17}$ The Macroprudential Policy Survey database contains information on the institutional aspects of the macroprudential policy framework in member countries. In addition, the database contains information on measures that may be taken with the objective of containing systemic risk-in line with the definition of macroprudential policy (IMF, 2013b) — and have been in place or were changed in 2017.
} 
(IMF, 2012). The criteria used to classify and assess measures are those set forth in the Institutional View and its related guidance (IMF, 2013a). As such, CFMs are defined as measures that are designed to limit capital flows. Specifically, CFMs comprise two types of measures: (i) residency-based measures, which are measures affecting cross-border financial activity that discriminate on the basis of residency (i.e., between residents and nonresidents); and (ii) other CFMs, which are measures that do not discriminate by residency but are nonetheless designed to limit capital flows. CFM/MPMs (i.e., CFMs that are also classified as macroprudential measures) are measures that are designed to limit capital flows and to reduce systemic financial risks stemming from such flows.

Using this information, we construct for each country in our sample a time series (AddPolicy) that combines both MPMs and CFMs. ${ }^{18}$ The combined measure of MPMs and CFMs is defined as:

$$
\text { AddPolicy } y_{t}=\Delta C F M_{t}^{\text {Inflow }}-\Delta C F M_{t}^{\text {Oufflow }}+\Delta M P M_{t}
$$

where:

- $\triangle C F M_{t}^{\text {Inflow }}$ take the value +1 if we are dealing with a tightening or the introduction of a CFM on inflows, and -1 if we are dealing with a loosening or the removal of a CFM on inflows in quarter $t$.

- $\quad \Delta C F M_{t}^{\text {Oufflow }}$ take the value +1 if we are dealing with a tightening or the introduction of a CFM on outflows, and -1 if we are dealing with a loosening or the removal of a CFM on outflows in quarter $t$.

- $\triangle M P M_{t}$ take the value +1 if we are dealing with a tightening or the introduction of a MPM, and -1 if we are dealing with a loosening or the removal of a MPM in quarter t. ${ }^{19}$

As anticipated above, the aim here is to explore the propensity of these policy actions to mitigate or amplify a given policy response in the face of exogenous capital flow pressures. This is done by interacting the shock (Shock) with such an additional policy variable (AddPolicy) in each of the 3 equations in (2) and for each country of interest, while also controlling for this additional policy variable as a regressor on its own in each of the regressions. Thus, estimates of $\hat{\beta}_{s p}^{\alpha}$, reflect the (mitigating or amplifying) impact — on a given future policy response and for a given percentile $\alpha$ of the distribution - of implementing additional, unconventional policy actions in the quarter in which an exogenous capital shock hits the economy.

\footnotetext{
${ }^{18}$ From an empirical viewpoint, nothing would prevent us from looking at the complementarity role of MPMs and CFMs separately. Similarly, it is possible to extend the current framework to examine the impact of other complementary policies, such as fiscal measures or macro-structural reforms. These extensions of the current model specification will be considered in the future.

${ }^{19}$ While the sign of the impact of CFMs on gross in/outflows is clear, in the case of MPMs this may be less obvious given that these measures often target net rather than gross positions.
} 


\section{Country-Specific Policy ReSponseS}

Can we assess the likelihood that-under certain domestic and global macro-financial conditions - a given country will deploy a given policy move tomorrow in response to a global portfolio flow shock hitting the economy today? Can we monitor how such a likelihood is likely to shift over time - as external shocks wane or intensify, and/or as domestic and global macro-financial conditions change? To illustrate the usefulness of the methodology for bilateral policy surveillance purposes and risk monitoring, we use Peru as a case study.

\section{Case Study: Peru}

While Peru has been adhering to an inflation targeting regime since 2002, the Peruvian authorities have continued to intervene frequently with the objective of smoothing volatility in the FX market (Figure 5). Financial vulnerabilities resulting from currency mismatches have been one of the rationales behind the frequent use of FX intervention: owing to the relatively high degree of financial dollarization of the economy, minimizing sharp and unexpected exchange rate depreciations has been key to avoid perverse balance sheet effects in the economy and ensuing large output contractions (Armas and Vega, 2019).

Figure 5: Peru. Published and Estimated FX Intervention

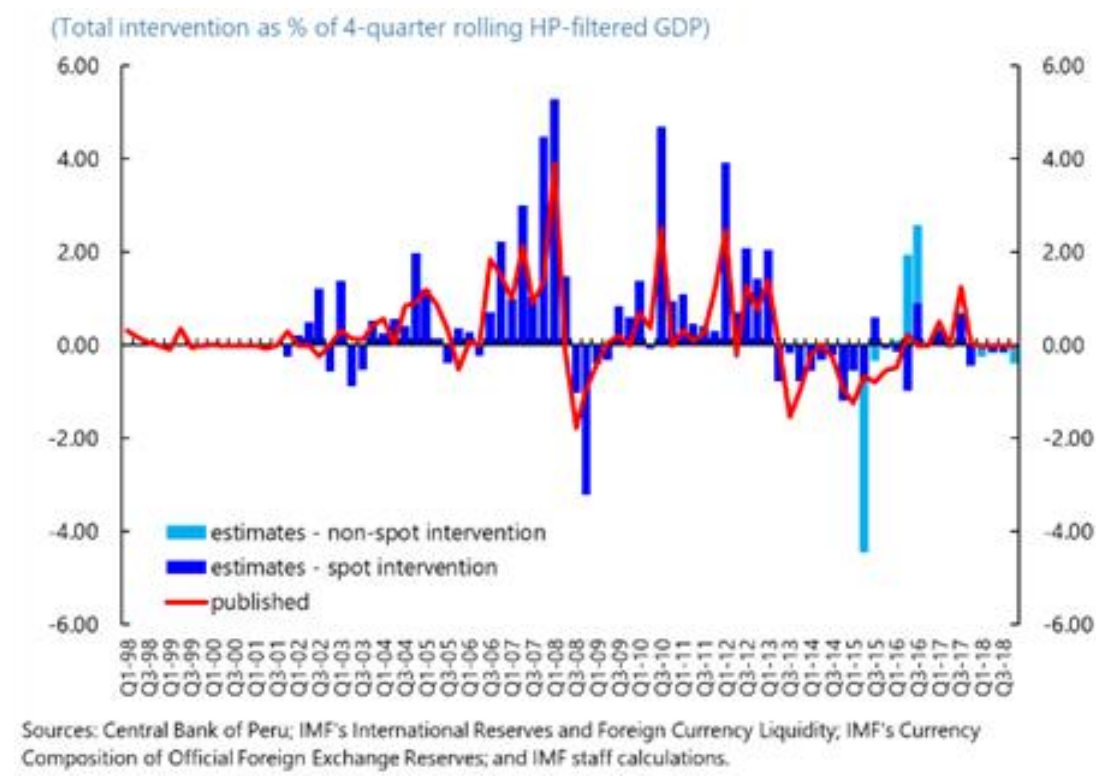

Overall, the long history of intervention episodes in Peru shows distinct features. A remarkable bout of intervention started in 2002 and ran through 2007, with net purchases of U.S. dollars totaling \$20 bln or 27 percent of GDP over the whole period. In this episode of steady capital inflows, purchases of foreign currency had a precautionary motive - that is, the increase of buffer stocks to provide needed FX liquidity in the face of potential negative external shocks and capital flow reversals. This unprecedented reserve accumulation was abruptly followed by the global financial crisis of 2008-09. From June 2008 to February 2009, $\$ 7.1$ billion (about 6 percent of 2009 GDP) were sold to avoid triggering negative 
balance sheet effects stemming from the dollarization of the financial system. After the global financial crisis, capital inflows and reserve accumulation resumed, which ended with the reversal of capital flows brought about by the tapering of quantitative easing in advanced economies in May 2013, the China's slowdown, and the sharp decline of commodity prices which continued until Q1 2016. Between 2013 and 2016, the sol depreciated as much as 35 percent. The tapering period is another remarkable episode of leaning against depreciation winds, with net FX sales of about $\$ 4.2$ bln and $\$ 8.1$ bln in 2014 and 2015, respectively. ${ }^{20}$

To monitor in real time expected changes in Peru's policy responses to external shocks and assess whether, ex-post, such responses may be deemed as "typical" or "extreme"-given prevailing macro-financial conditions at the time of the forecast - we fit a t-skewed distribution to the predicted values from the country-specific quantile regressions discussed in the previous section and compute conditional forecast distributions of FX intervention, monetary policy changes and exchange rate changes. For each of the three policy responses considered and for each quarter, Figure 6 reports actual average policy changes over the next two quarters (black solid line) as well as corresponding predictions of downside tail risks (red dashed line) and upside tail risks (green dashed line) to those changes.

At each point in time, the top chart of Figure 6 shows how Peru's conditional forecast distribution of FXI over the next two quarters has varied over time, depending on prevailing shocks, global and domestic macro-financial conditions. The middle and bottom panel show corresponding shifts in the conditional forecast distribution of Peru's policy rate and exchange rate changes, respectively.

The "at-risk" framework seems to predict quite well average Peruvian policy moves over the next two quarters, with realized policy changes falling within the predictive distribution's 10th-90th percentile range quite consistently in all three cases. A few remarkable policy actions represent exceptions - such as the large FX purchase in 2007, the extreme monetary policy loosening in 2009, and the strong depreciation pressures on the sol in mid-2018.

\footnotetext{
${ }^{20}$ For more details on the evolution of Peru's policy framework, see also Ghazanchyan et al. (forthcoming).
} 
Figure 6: Conditional Forecasts of Peru's Short-Term Policy Responses
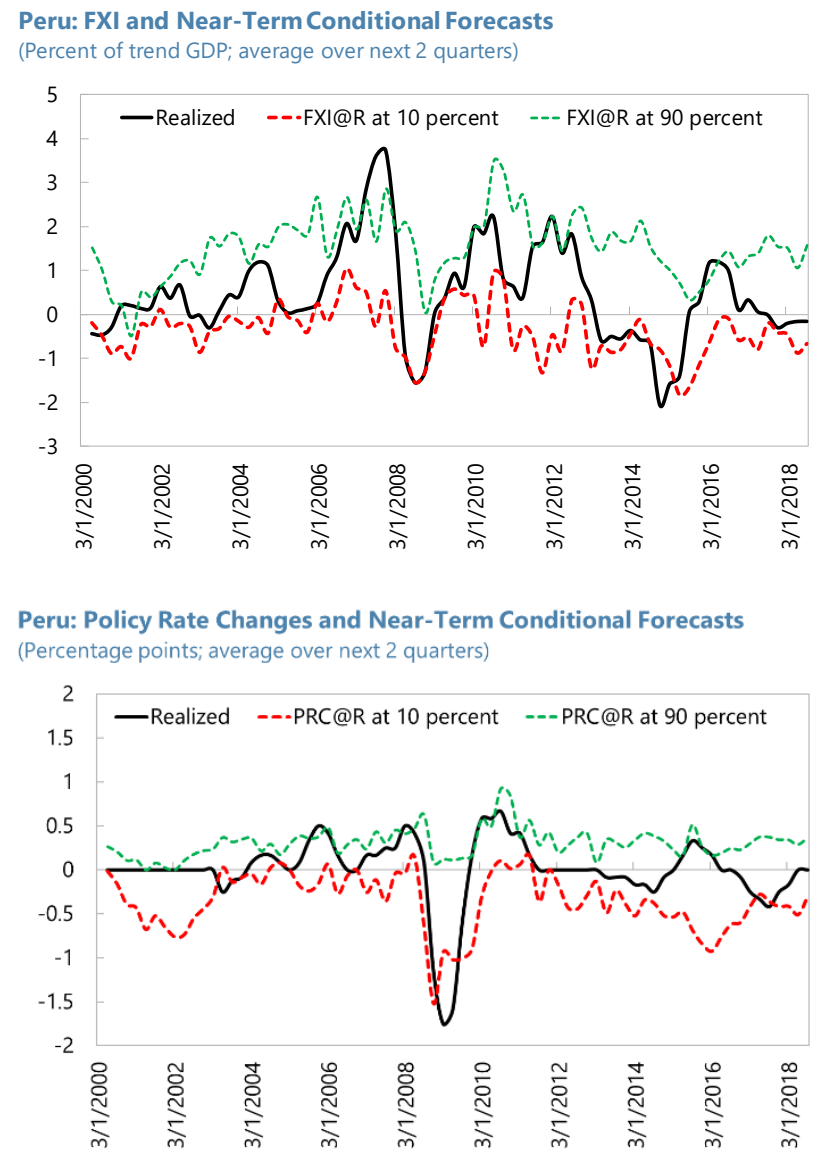

Peru: Exchange Rate Changes and Near-Term Conditional Forecasts (Percentage changes; average over next 2 quarters)

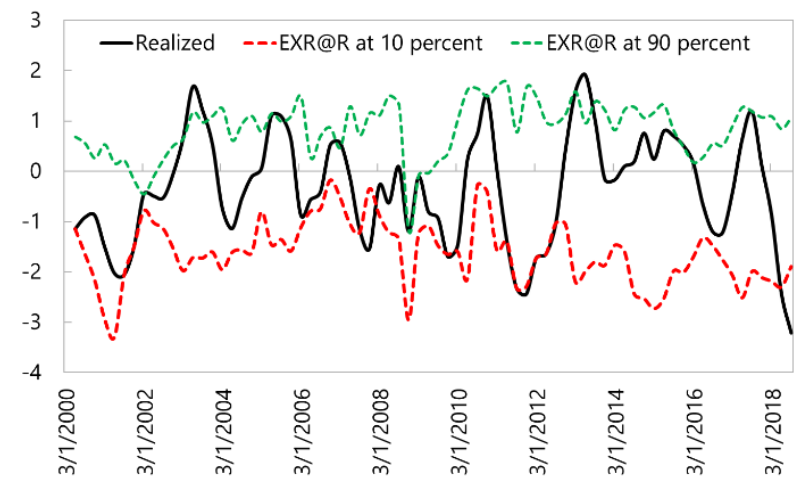

Source: Haver, Bloomberg LP, and IMF Staff Estimates

Notes: At each point in time, the figure reports realized average policy changes over the next two quarters (black solid line) as well as corresponding predictions of downside tail risks at the $10^{\text {th }}$ percentile (red dashed line) and upside tail risks at the $90^{\text {th }}$ percentile (green dashed line) to those changes, estimated from in-sample predictive densities over the period Q1 2000-Q3 2018. 
Estimates of tail risks to policy responses display substantial variation over time and across different types of responses. For example, from 2003 and 2007, amid large and persistent inflow shocks, the likelihood of future extreme $F X$ purchases appears to have gradually increased: in 2007, the framework predicted a 10 percent chance that FX purchases over the following two quarters would average at least 3 percent of GDP compared to a forecast of at least 1 percent of GDP in 2003. However, no obvious shift in the likelihood of extreme future exchange rate appreciations or policy rate changes was foreseen over the same periodmeaning that the observed "FXI-only" policy response to persistent inflows was consistent with prevailing shocks and macro-financial conditions. On the other hand, in the face of adverse external shocks between 2011 to 2015, estimated forecast distributions seem to indicate a different outcome. Under those circumstances, not only higher chances of extreme $F X$ sales were anticipated, but also slightly higher chances of extreme monetary policy loosening and extreme exchange rate depreciation, suggesting some asymmetry of policy actions over the cycle.

The "at-risk" approach can also be helpful in assessing how the distribution of short-term policy responses - and associated tail risks - have shifted following a given episode. For example, we can study how the short-term outlook of Peru's policy responses has changed between Q3 2016 and Q3 2018, as the U.S. Fed began to tighten monetary policy. The way in which the distribution of future flows evolved was strikingly different with respect to the 3 types of policy responses (Figure 7). For FXI, Figure 7 shows a deterioration in the central estimate of expected intervention over the next 2 quarters (from a conditional mean of 0.5 percent of GDP to a conditional mean of -0.1 percent of GDP) and a sharp increase in downside risks: the probability of short-term FX sales soared between Q3 2016 and Q3 2018 from 21 to 46 percent of GDP (with a 5 percent chance that Peru's FX sales over the next 2 quarters would be at least 1.6 percent of GDP as of Q3 2018, rather than by just 1.1 percent of GDP, as predicted 4 quarters earlier). Conversely, the conditional forecast distribution of policy rate changes is virtually unchanged between Q3 2016 and Q3 2018, meaning thatgiven prevailing global and domestic macro-financial conditions at those times - the future monetary policy stance was not expected to change in the face of the observed external shock. Mirroring the strong currency depreciation occurred over 2017-18, the short-term central outlook for exchange rate responses has actually improved between Q3 2016 and Q3 2018: from a conditional mean of -0.38 percent (depreciation) to a conditional mean of +0.13 percent (appreciation) and a probability of further depreciation receding from 70 to 55 percent. Downside risks, however, remain substantial, with a 5 percent chance that the sol would depreciate over the next 2 quarters by at least 3.2 percent as of Q3 2018, rather than by 2.4 percent, as predicted 8 quarters earlier. 
Figure 7: Predicted Distribution of Peru's Short-Term Policy Responses, 16Q3 vs 18Q3
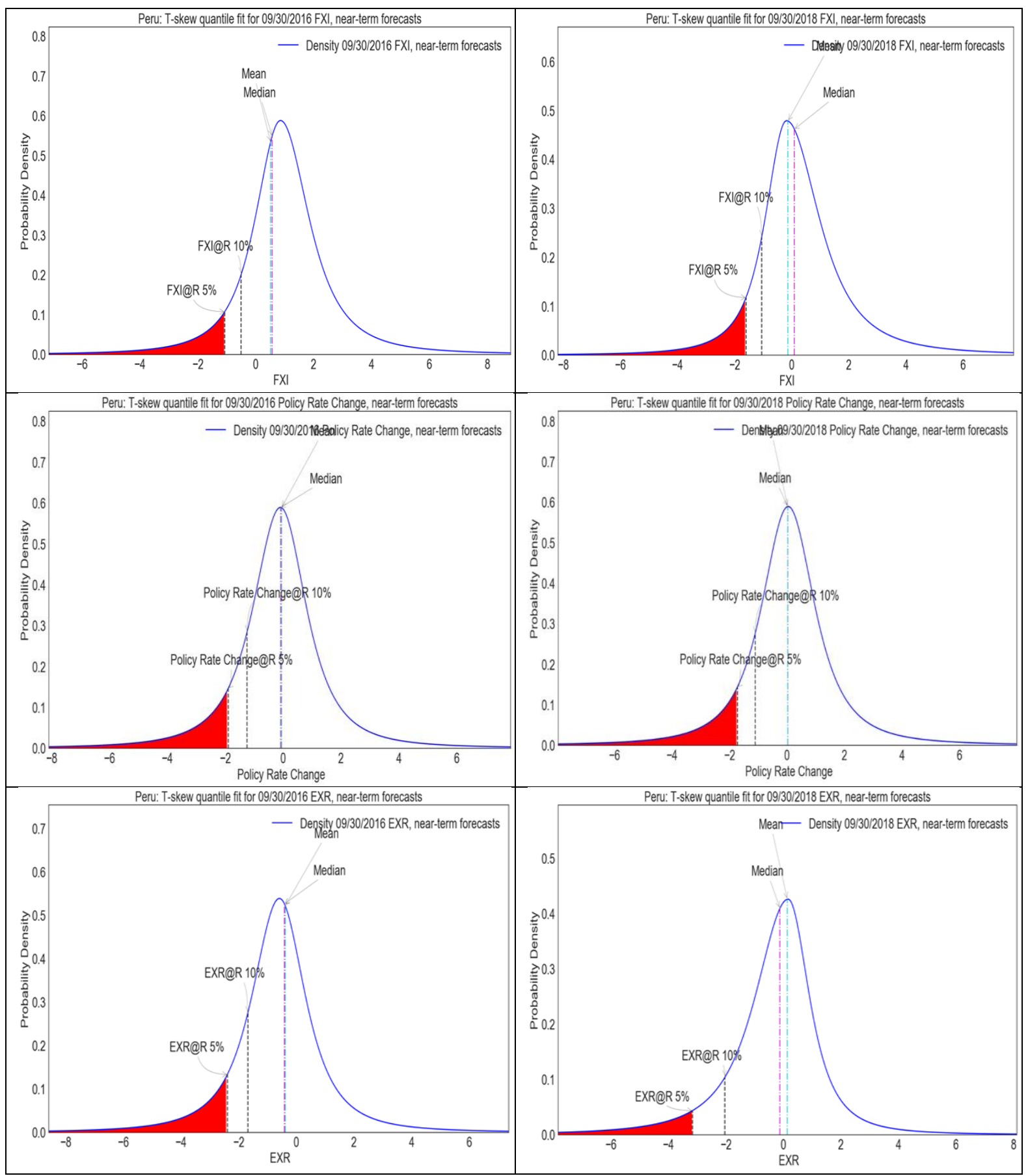

Source: Haver, Bloomberg LP, and IMF Staff Estimates

Notes: The figure reports conditional densities for average Peru's FXI (top charts), policy rate changes (middle charts), and exchange rate changes over the following two quarters (bottom charts), predicted using information up to Q3 2016 (left charts) and using information up to Q3 2018 (right charts). Red areas indicate downside (tail) risks at the $5^{\text {th }}$ percentile. 
Finally, we perform a scenario analysis to assess how the short-term outlook for Peru's policy responses would change following a significant adverse shock to global flows. To do this, we simulate the effects of a sharp, exogenous drop in global portfolio inflowsmeasured by a fall of two times their standard deviation over the sample (approximately 0.46 percent of emerging markets' trend GDP) — and compare the corresponding two-quarter ahead forecast distribution of FX intervention, policy rate changes, and exchange rate changes with baseline predictions at the end of the sample. As shown in Figure 8, top-right chart, as exogenous portfolio inflows shrink, the odds of FX sales over the next two quarters increase significantly with respect to the 2018Q3 baseline, from 46 to 80 percent (alternative: green line; baseline: red line). Downside risks to FX intervention also increase. On the contrary, under such a risk scenario, the conditional distribution of interest rate changes remains virtually unchanged (mid-right chart), while the exchange rate is expected to depreciate slightly (bottom-right chart).

To highlight the importance of asymmetric responses, we also simulate the effects of a samesize increase in global portfolio inflows - namely, 0.46 percent of emerging markets' trend GDP (Figure 8, left-had side charts). Both FXI responses and exchange rate responses appear to be smaller in the face of inflow shocks than in the face of outflow shocks, while no interest rate response continues to be predicted in either case.

Finally, we study the role played by additional policies - such as MPMs and CFMs - in mitigating the impact of an exogenous inflow shock on Peru's FXI, monetary policy and exchange rate responses. To quantify such an impact, Figure 9 shows separately (i) the standalone effect from the additional policies (top charts) and (ii) the interaction between the additional policies and the external shock (bottom charts). If the implementation of the additional policies mitigates the impact of an exogenous inflow shock on a given future policy response at a given percentile $\alpha$, the total effect should be a reduction in the magnitude of the policy response in absolute terms. Vice versa if the action amplifies the effect of the shock.

Overall, in the case of Peru, the use of additional policy measures in response to an exogenous capital flow shock appears to be associated with lower extreme FX sales (corresponding to the lowest percentiles of the predicted conditional distribution for FXI) in the near future, while the total mitigating impact vis-à-vis extreme FX purchases appears to be negligible. We also find that the use of these extra measures can make interest rate hikes more likely following an exogenous inflow shock of foreign capital. The use of additional policy measures also appears to mitigate the impact of external shocks on extreme exchange rate appreciation and depreciation in the near future, even though this effect is not found to be statistically significant. 


\section{Figure 8: Impact of Exogenous Portfolio Flow Shocks on Peru's Short-Term FX Intervention-Risk Scenario}
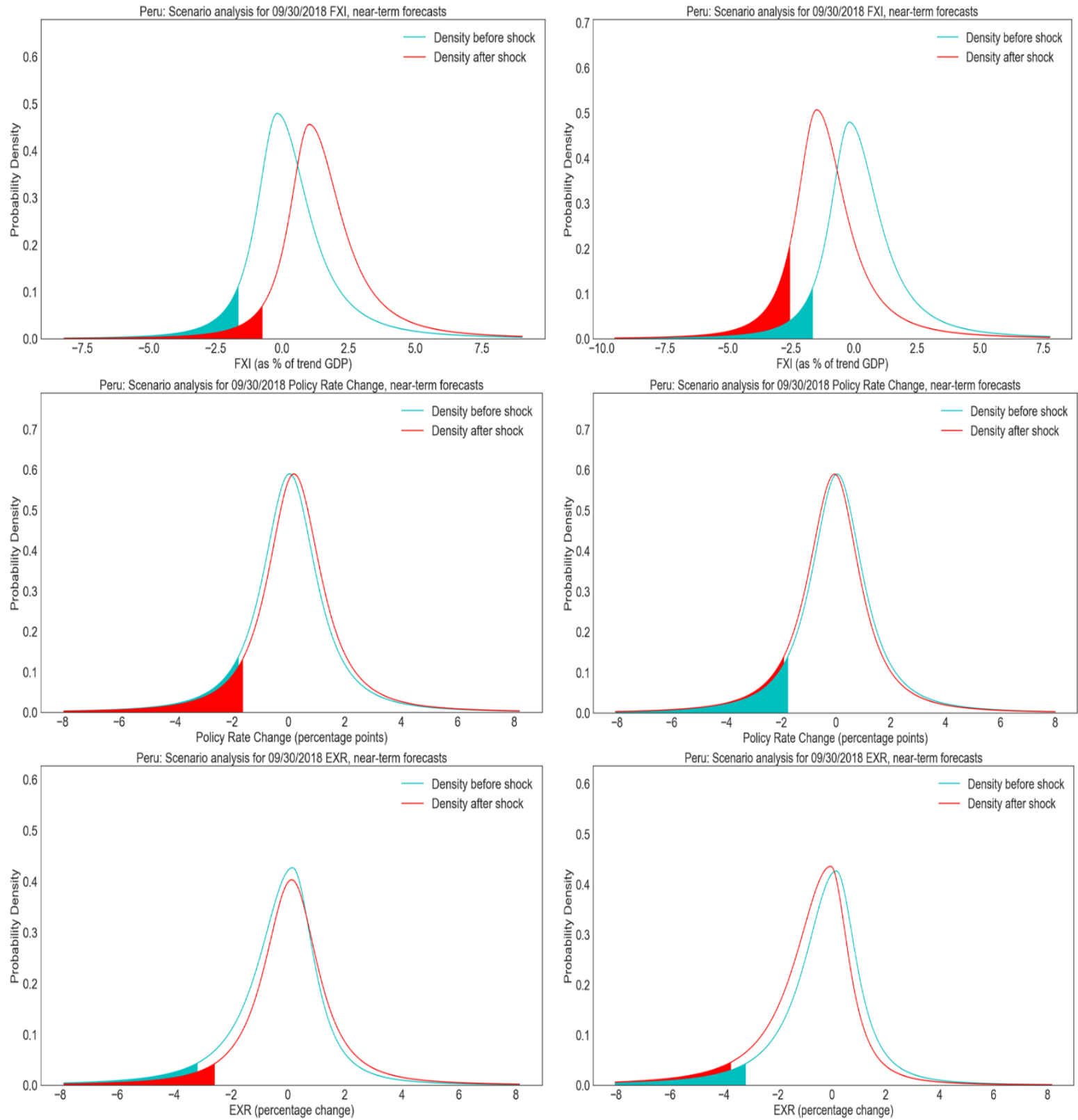

Source: Haver, Bloomberg LP, and IMF Staff Estimates

Notes: The turquoise lines show the fitted distributions of portfolio inflows for Q4 2018-Q1 2019 predicted in Q3 2018 for Peru FXI (top panel), policy rate changes (middle panel), and exchange rate changes (bottom panel). The turquoise shaded areas beneath these distributions indicate downside tail risks at the $5^{\text {th }}$ percentile in the absence of any shock. The red lines show the predicted distributions for the same horizon, but under the assumption that global portfolio inflows fall (right hand-side charts) or rise (left hand-side charts) by two times their standard deviation (e.g., 0.46 percent of trend GDP for all other EMs) over the sample. The red shaded areas beneath these distributions indicate downside tail risks at the $5^{\text {th }}$ percentile in the presence of the shock. 
Figure 9: Drivers of Peru's Policy Responses

Selected Standardized Quantile Regression Coefficients

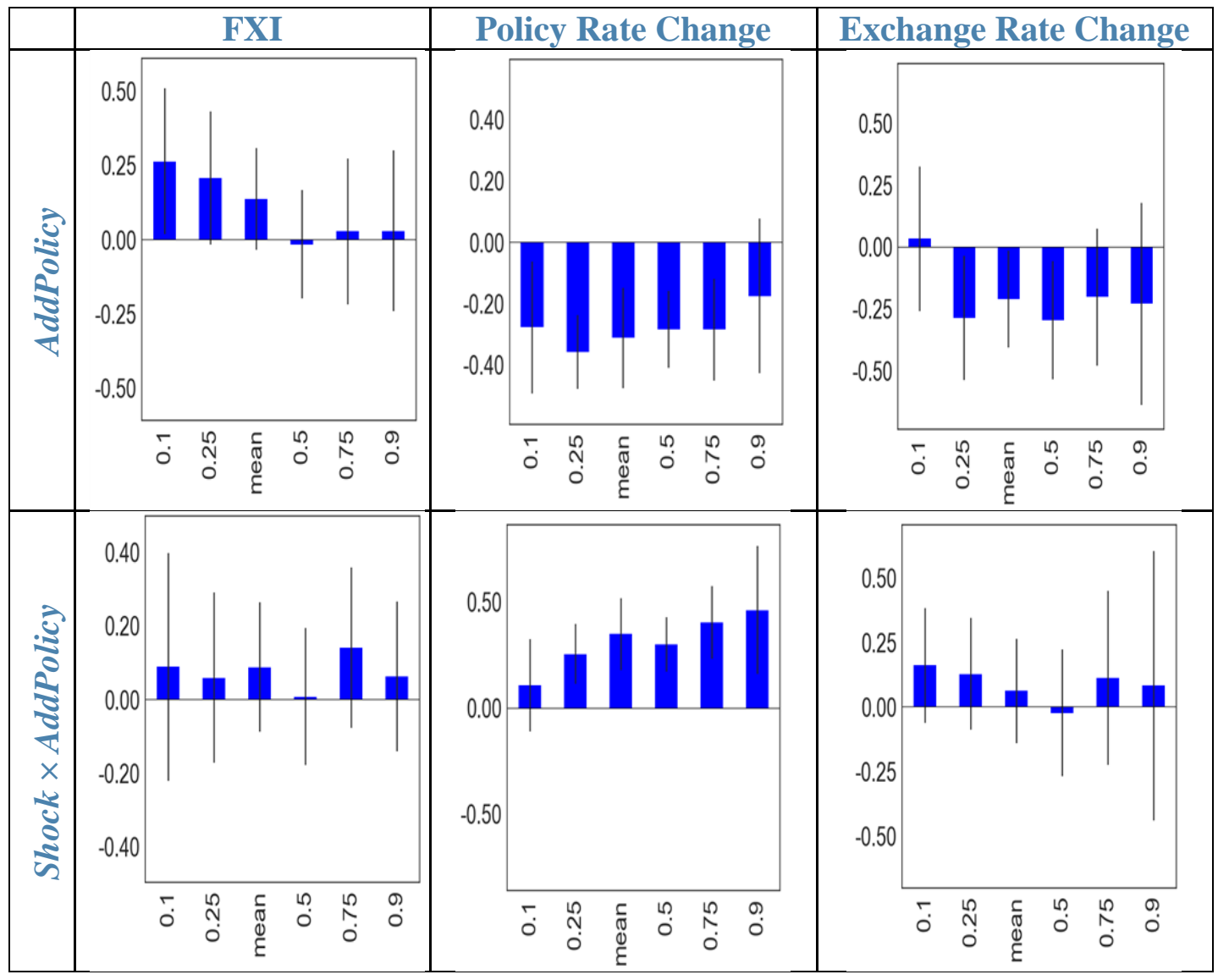

Source: Haver, Bloomberg LP, and IMF Staff Estimates

Notes: With respect to Peru's FX intervention (lhs), policy rate (middle), and exchange rate changes (rhs), the panel shows coefficient estimates and one-standard deviation confidence bands for the impact of exogenous portfolio flow shock variable (top charts), additional policy variable (middle chart) and the interaction term between the shock and the policy variable (bottom charts). See section II.A in the text for regression specification details.

\section{Rationalizing the Cross-Section of Policy Responses}

From a multilateral surveillance perspective, our empirical framework facilitates a more systematic understanding of observed cross-country differences in the choice of the policy mix vis-à-vis external shocks. Looking at the cross-section of responses to the capital flow shock helps to clarify the motivation/concerns behind countries' policy reactions.

This section explores whether cross-country differences in policy responses to essentially the same shock can be associated with certain country characteristics — such as country's degree of capital account openness, size of balance sheet vulnerabilities, degree of FX market depth, and so on. To do this, we consider each country's predicted responses to the exogenous capital flow shock over the following two quarters and check whether those correlate with any given country characteristic of interest. The characteristics we focus on are either slow moving or infrequently measured. At such, these factors cannot be controlled for in equation 
(2) or they would be subsumed in the country-specific constant term. ${ }^{21}$ Because we simply consider raw correlations between characteristics and policy responses, there is no presumption of uncovering any causality between the two.

\section{A. Average Policy Responses Across Countries}

Consider the intensity of a country's policy reaction to a capital flow shock. It conflates two factors. The first one is related to the degree of country's exposure to the shock: the more a country is exposed to the shock, the larger is likely to be its reaction to it. The second onewhich is subsumed in coefficient $\beta_{s, .}^{\alpha}$ in equation (2) - is the strength of the country's policy reaction that is due to its inherent features as well as to idiosyncrasies in its policy approach that are anyway unrelated to its exposure to the shock, making it react differently even when facing the same-sized, global shock. By first identifying an exogenous, samesized global shock and then correlating estimated country-specific reactions with their potential determinants, we can try to disentangle the two factors.

Figure 10 shows that policy responses to capital flow shocks are indeed highly heterogeneous across countries even after controlling for cyclical conditions and an exogenous, same-sized shock to global flows., They differ not only at their median, but also in their degree of skewness and fat-tailness.

The first three charts (two at the top and bottom left) present responses of FX intervention, exchange rate and interest rate changes, using 4 bars:

- Heterogeneity. In all three charts, the first bar (labeled as "Heterogeneity: median response") illustrates the cross-country heterogeneity of responses by plotting the min-max range of the average 2 -quarter ahead median $\left(50^{\text {th }}\right.$ percentile $)$ responses, $\beta_{s, .}^{50}$, as well as the median response across all countries. The range is wide for all three key variables. For example, for FX intervention the average 2-quarter ahead response to a portfolio inflow of 1 percentage point of GDP varies between purchases of FX of 2 percentage points of GDP to sales of FX of -1 percentage points of GDP.

- Skewness. The second bar (labeled as "Skew: $90^{\text {th }}-10^{\text {th") }}$ illustrates the extent to which responses are skewed by plotting the min-max range across countries of the difference between average 2 -quarter ahead $90^{\text {th }}$ percentile responses and $10^{\text {th }}$ percentile responses, $\beta_{s \text {. }}^{90}-\beta_{s,}^{10}$, as well as the median skew. In the case of FXI, the median skewness is close to zero, but clearly several countries have assymetric responses, in particular FX intervention responses are heavily negatively skewed for

\footnotetext{
${ }^{21}$ One alternative would be to run a panel and interact some of these characteristics with each control and shock. This assumes that the large degree of heterogeneity would be fully captured by a few key characteristics, which is unlikely. An additional complication is that one would quickly lose power and exhaust degrees of freedom in a quantile regression framework, as interactions quickly lead to many more independent variables. We choose to focus on country-specific estimates of the policy responses and evaluate correlations between characteristics and policy responses in a second step.
} 
some. For both exchange rates and interest rates, even the median country has a negative skew, and several countries exhibit very large left-tail responses. All these point to the fact that extreme responses are larger when selling FX, the exchange rate is depreciating and policy rates are being cut.

\section{Figure 10: Responses: Heterogeneity, Skewness and Fat Tails}

FX intervention (+=purchase, in percent, response to a one percent of GDP global flow to EMs)

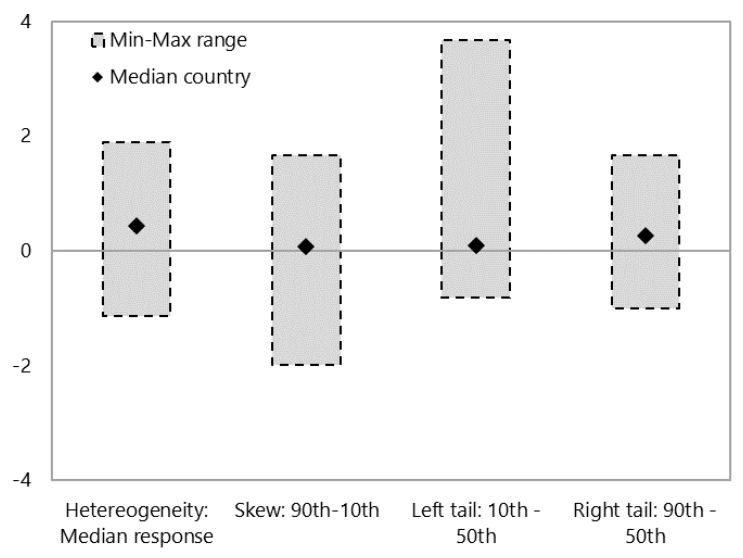

Exchange Rate Movements (+=appreciation, in percent, response to a one percent of GDP global flow to EMs)

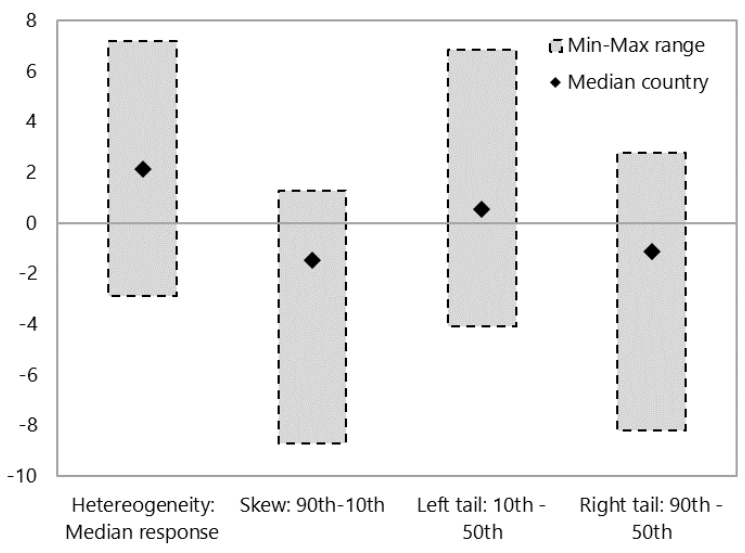

Policy Rate Movements (+=hike, percentage points, response to a one percent of GDP global flow to EMs)

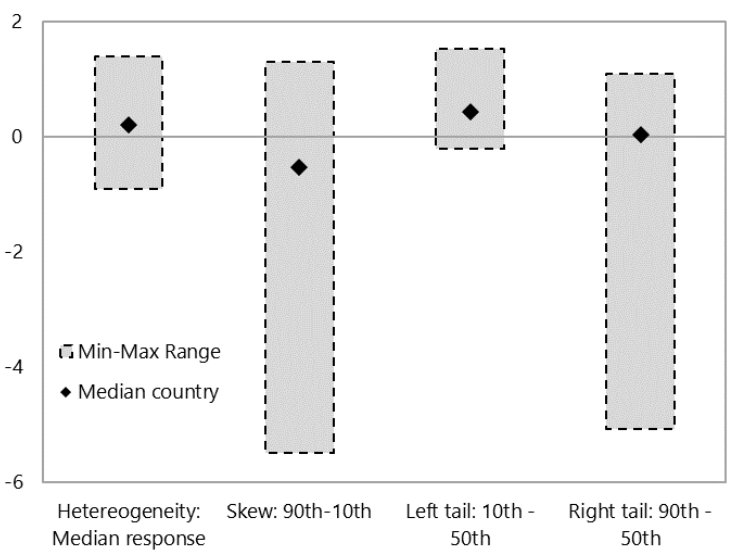

Median Responses (+=purchase, appreciation or hike, in percent except interest rates in percentage points, response to a one percent of GDP global flow to EMs

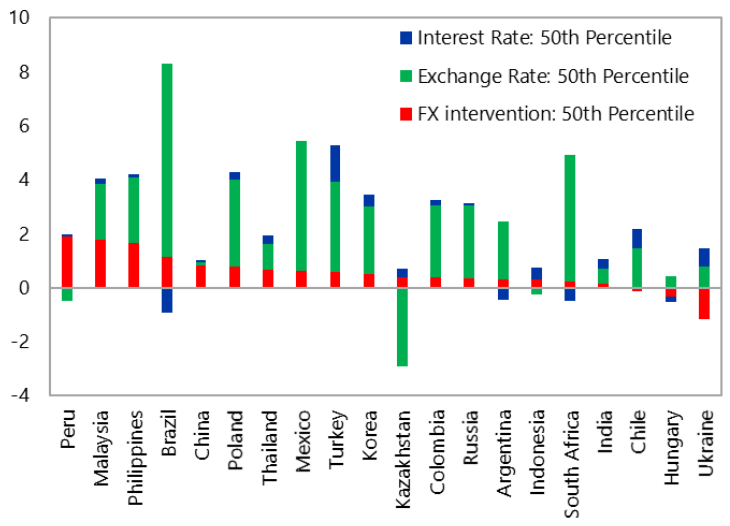

Source: IMF Staff Estimates

Notes: The chart shows average two-quarter ahead policy responses estimated by running equation (2) shown in percentage points across all panels. The first three charts (both at the top and bottom left) show summary statistics across all countries documenting that responses are heterogeneous, skewed and fat-tailed as discussed in the main text. The last chart (bottom right), shows the country-level detail of the left-most bar of each of the three previous sub-charts.

- $\quad$ Fat tails. The third and fourth bars (labeled as "Left tail: $10^{\text {th }}-50^{\text {th }}$ and Right tail: $90^{\text {th }}$ $-50^{\text {th }}$ ) illustrate the degree to which responses are either left or right fat-tailed compared to the median response by plotting the min-max range across countries of the difference between average 2-quarter ahead of each extreme response to the median, as well as the median fat-tailness on each side. For FX intervention, both left and right tail responses seem larger than the median response, the left tail is particularly large, consistent with the finding that FX intervention has more often 
than not a highly negative skew. For both exchange rates and interest rates, the left tail is also in general thicker, but the right tail is thinner, again both consistent with the finding there that most responses were overwhelmingly negatively skewed.

The last chart of Figure 10 (bottom-right) gives the country detail behind the first bar of the first three charts. Countries are ordered by their average 2-quarter ahead FX intervention median responses. The heterogeneity comes through clearly: for example, Peru responds the most in terms of FX intervention, but its exchange rate barely moves. Others see large exchange rate movements without much intervention (e.g. South Africa), or adjust their policy rates more vigorously (e.g. Turkey).

Figure 10 provides a consistent picture: responses to external capital flow shocks vary tremendously across countries, both qualitatively and quantitatively. The obvious question that follows is why that would be the case.

\section{B. Linking Policy Responses and Country Characteristics}

We explore a large set of country characteristics that could be behind why countries choose different policy responses in the face of global capital flow shocks. Some of the determinants considered here include: (i) proxies for balance sheet vulnerabilities and buffers, such as the size of domestic banks' net open FX position, the ratio of short-term debt in foreign currency to forex reserves, the structure of external assets and liabilities, or the level of reserve adequacy; (ii) the degree of trade and capital account openness; (iii) indicators of financial market depth, such as an index of overall financial market development, the degree of turnover in the local currency FX market, or the corresponding ask-bid spread; (iv) structural indicators, like the exchange rate regime, the share of trade invoiced in USD, the degree of Central Bank transparency, and so on. The full list of variables considered is detailed in Annex II.A., with corresponding sources.

Table 1 summarizes our findings across all characteristics for policy rate responses, forex intervention and exchange rate responses. Note that the table has many empty cells, where we did not find any statistically significant association between the corresponding structural characteristic and the policy response.

Monetary policy rate responses are mostly unrelated to country characteristics, probably reflecting the fact that countries usually rely on similar monetary policy frameworks. Such frameworks tend to respond primarily to changes in domestic cyclical conditions and cannot thus be linked to time-invariant, country-specific characteristics. The extent to which a currency is overvalued is a notable exception, being associated with looser monetary policy in "typical" and "extreme" loosening responses. This means that countries may be wary of using monetary policy if it risks pushing their exchange rate even more out of equilibrium. 
Table 1: Summary of the Link Between Characteristics and Policy Responses

\begin{tabular}{|c|c|c|c|c|c|c|c|c|c|}
\hline & \multicolumn{3}{|c|}{ Policy Rate Actions } & \multicolumn{3}{|c|}{ FX Intervention } & \multicolumn{3}{|c|}{ Exchange Rate } \\
\hline & $\begin{array}{l}\text { Extreme } \\
\text { Loosening }\end{array}$ & $\begin{array}{c}\text { Typical } \\
\text { Tightening }\end{array}$ & $\begin{array}{l}\text { Extreme } \\
\text { Tightening }\end{array}$ & $\begin{array}{l}\text { Extreme } \\
\text { Sales }\end{array}$ & $\begin{array}{l}\text { Typical } \\
\text { Purchases }\end{array}$ & $\begin{array}{l}\text { Extreme } \\
\text { Purchases }\end{array}$ & $\begin{array}{c}\text { Extreme } \\
\text { Depreciation }\end{array}$ & $\begin{array}{c}\text { Typical } \\
\text { Appreciation }\end{array}$ & $\begin{array}{c}\text { Extreme } \\
\text { Appreciation }\end{array}$ \\
\hline IIP, Portfolio Investment Asset (\%GDP) & & & & 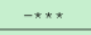 & & & & & $-\star \star$ \\
\hline IIP, Portfolio Investment Assets (\%Liabilities) & & & $-\pi *$ & $-\star \star \star \star x$ & & & $-\pi *$ & $--* * \star x$ & $-\star \star \star x$ \\
\hline IIP, Portfolio Investment Liabilities (\%GDP) & & & & & & & & $+\times *$ & \\
\hline \multicolumn{10}{|l|}{ Trade Openness } \\
\hline \multicolumn{10}{|l|}{ Capital Account Openness } \\
\hline \multicolumn{10}{|l|}{ Financial Market Development } \\
\hline FX Market Turnover (\%GDP) & & & & $-\star \star *$ & $-\star \star *$ & $-* \star *$ & & & \\
\hline Short-term FX Debt (\%Reserves) & & & & $+\times *$ & $-\pi$ & $-* * *$ & & & \\
\hline Net Open FX Positions (\%Bank Capital) & $+*$ & & & $+* x *$ & $--\star \star \star x$ & & & & \\
\hline REER Overvaluation & $+* * *$ & $-*$ & & & $+*$ & $+\star \star \star \star *$ & & & \\
\hline De-Facto Exchange Rate Flexibility (AREAER) & $-* * *$ & & & & & $-* * *$ & $+\star * *$ & $+\times \star *$ & $+\star \star * *$ \\
\hline USD Invoicing (\%Total Trade) & & & & & $+*$ & & & & $+* * *$ \\
\hline Reserves (\%ARA metric) & & & & $+*$ & $+* \star * x$ & $+\star * x$ & $-\star *$ & & \\
\hline
\end{tabular}

Source: IMF Staff Estimates

Notes: The table shows summary results for regressions of two-quarter ahead policy responses (columns) on country characteristics (rows). The columns cover median or "typical" responses and $10 / 90^{\text {th }}$ percentile or "extreme" responses for forex intervention and exchange rate changes. Highlighted in green are relationships that are one-sided statistically significant at the 10 percent significance level. Stars denote whether the relationship is significant at: * $10 \%$; ** 5\%; *** $1 \%$ significance level. The relevant t-statistic was computed for 18 degrees of freedom (20 countries -2 estimated coefficients).

On the contrary, FX intervention appears to be related to balance sheet vulnerabilities, buffers and the degree of average exchange rate overvaluation. Longer net open FX positions (or conversely shorter local currency positions) and larger short-term debt in foreign currency relative to reserves tend to be associated with larger forex reserve sales in the face of outflow pressures, but with smaller intervention in the face of inflow pressures (Figure 11). Larger forex reserve sales also tend to be associated with lower foreign assets as a share of GDP, suggesting that forex intervention could potentially be substituting for the lack of a domestic investor base able to repatriate capital at times of non-resident outflows. Reserves are also positively correlated with FX intervention in both directions. While the fact that reserves are correlated with FX purchases is not surprising and may be attributable to reverse causalityi.e. the more you buy the more reserves you tend to have - the relationship with sales is more interesting. One interpretation is just that interventionists tend to have higher reserve stocks and do two-sided interventions. Another, complementary interpretation may be the existence of a floor on reserves that interventionists with low levels of reserves are unwilling to break: this may limit their sales in the face of outflows.

It is important to stress that statistical correlations do not imply any causality. Indeed, while pre-existing structural characteristics of the economy may have favored interventionist policies, it is also true that interventionist policies may have also contributed to persistent shallowness in FX markets, for example by hindering the development of instruments for FX hedging. Equally, arguably, balance sheet mismatches and liability dollarization in the banking system may have been more persistent than they would have been if the gains from transitioning to an inflation targeting regime had been paired with a more flexible exchange rate. 
Figure 11: Link Between FX intervention and Net Open Positions of Domestic

\section{Banks / FX market turnover}
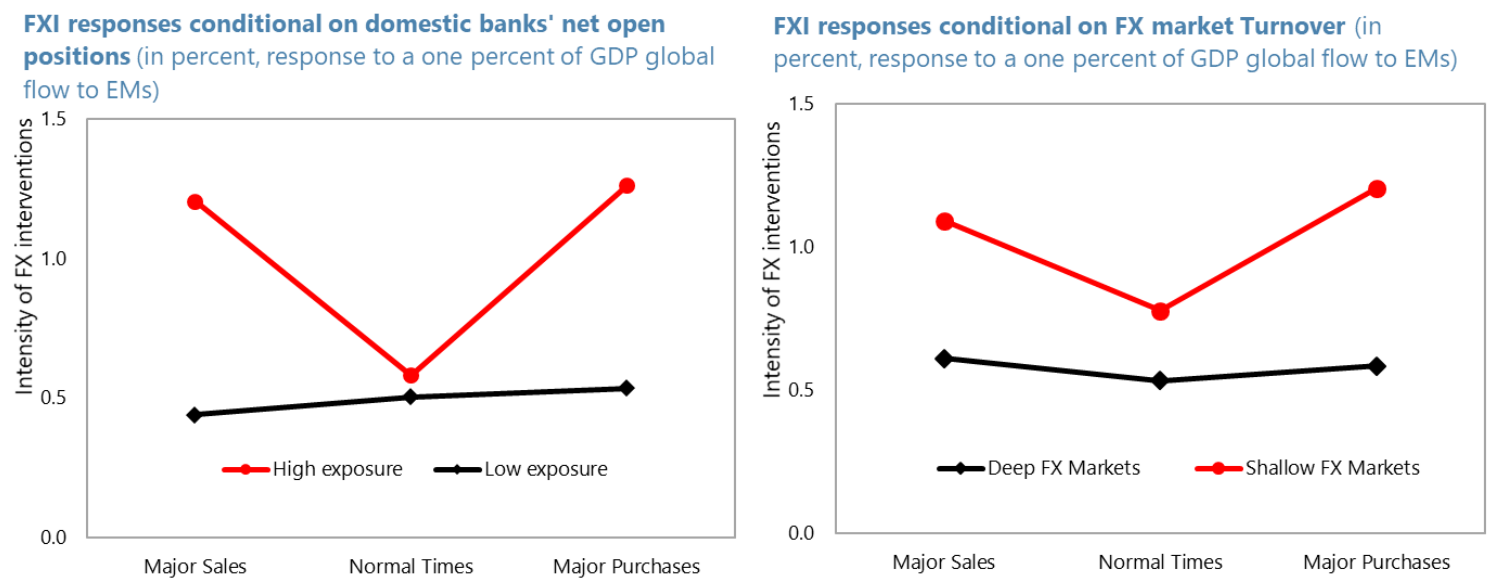

Sources: IMF Staff Estimates

Notes: The figures show the average two-quarter ahead FXI averaged across countries depending on whether they are above or below the median for each of the two characteristics. Averages are taken for responses at the $10^{\text {th }}$ percentile ("Major Sales"), the $50^{\text {th }}$ percentile ("Normal Times") and the $90^{\text {th }}$ percentile ("Major Purchases"). See Annex II.B for the definition of the two characteristics shown.

Finally, the relationship between exchange rate responses and country-specific characteristics seems to be somewhat weaker. This may imply no systematically different exchange rate responses between interveners and non-interveners countries. Two characteristics seem, however, to be associated with different exchange rate responses: (i) the Net International Investment Position (NIIP) matters; (ii) the degree of de facto exchange rate flexibility. The latter is tautological: if de facto exchange rate flexibility is measured correctly, one would expect those with more flexible currencies to see higher appreciation/depreciation for the same type of shock. The former is less obvious and may suggest that countries with substantial foreign assets relative to foreign liabilities witness less exchange rate movements than their peers. This may be explained by the fact that resident portfolio flows offset nonresident flows in any direction; alternatively, this could be due to the fact that the marginal investor perceives such countries as less risky, hence demanding relatively lower risk premia in the face of external shocks.

\section{The Role of Additional Policy Tools}

This section explores the interactions of additional policy tools - such as MPMs or CFMswith the policies studied in the previous sections - namely, monetary and exchange rate policies. In particular, it assesses the tendency of these tools to mitigate or amplify monetary and exchange rate responses in the face of exogenous capital flow pressures.

It is important to keep in mind that only a subset of countries in our sample has implemented these policies. In addition, we only focus on statistically significant country-specific interactions of these additional policies with the exogenous shock. Thus, any conclusions in this section on how additional policies shift responses across countries are inherently driven by the few countries that have used these policies effectively. The existence of potential 
longer-term, unintended consequences from the use of these unconventional policy tools could well explain why some countries refrain from adopting them in the first place.

Overall, we find that in those cases in which these additional policy tools are used effectively: (i) monetary policy actions become more in-line with future expected inflation developments, even though "typical" country responses do not appear to be very much affected; (ii) FX intervention and exchange rate responses to inflow and outflow pressures become more asymmetric; (iii) country-specific portfolio flows respond more over the medium-term (2 year horizon) than over the short-term (2-quarter horizon). We discuss each of these three points in the following subsections.

\section{A. Additional Policy Tools and Monetary Policy}

Our first finding is that additional unconventional policy tools allow monetary policy to more squarely focus on its domestic inflation stabilization mandate. Figure 12 summarizes the coefficients with and without additional policy actions, where, as mentioned above, the former considers significant coefficients only. ${ }^{22}$ In the presence of inflow pressures, interest rates tend to be set higher if additional policies are deployed significantly. Conversely, in the presence of outflow pressures, interest rates tend to be set lower.

\section{Figure 12: Additional Policies Appear to Affect Monetary Policy Responses}

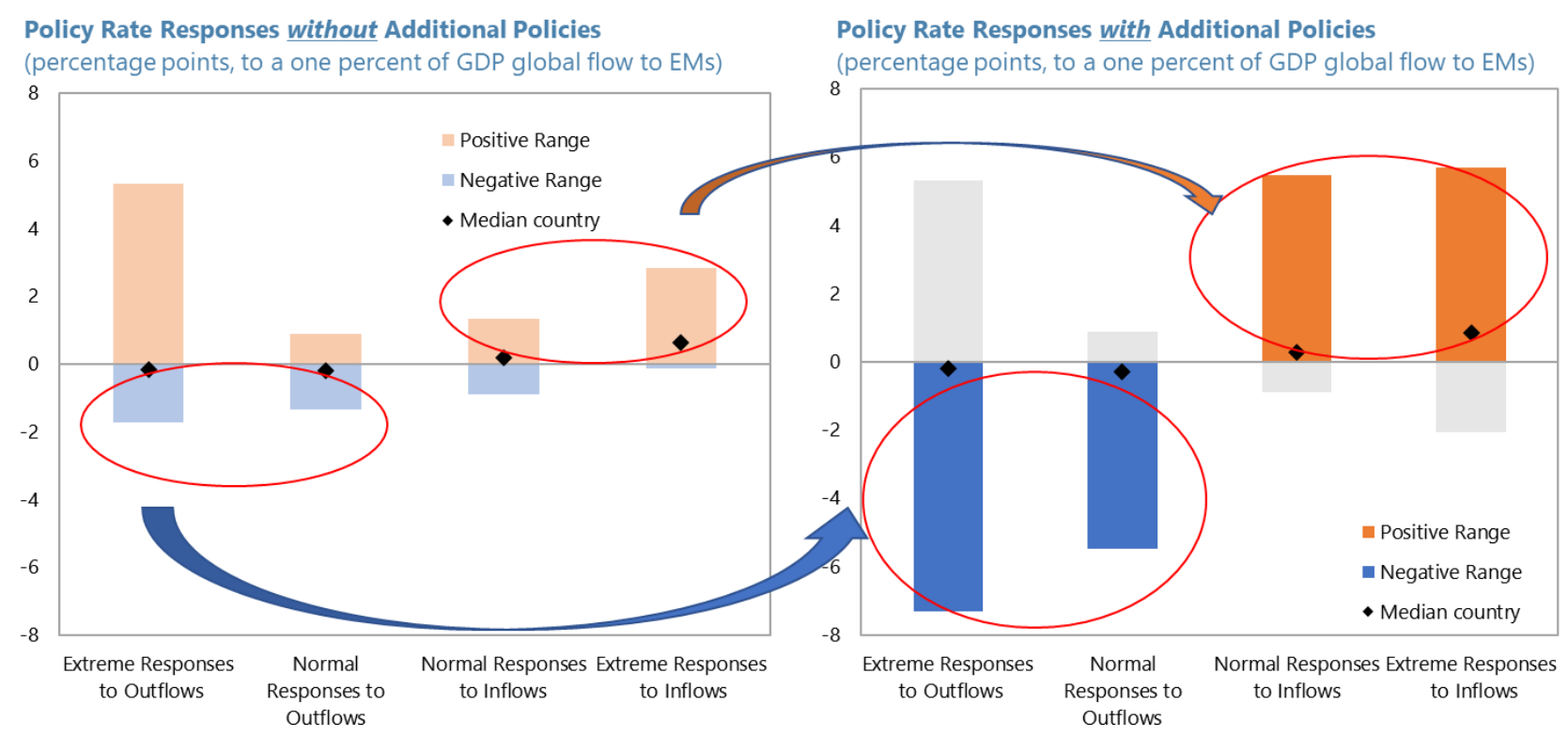

Sources: IMF Staff estimates.

Notes: The chart shows the full range of average two-quarter ahead coefficients across countries. The chart on the left shows only unconditional coefficients, e.g. ( $\left.\beta_{s,}^{\alpha}\right)$ in equation $(2)$, while the chart on the right adds the interaction coefficient between the exogenous shock and the additional policy variable , e.g., $\left(\beta_{s, .}^{\alpha}+\beta_{s p, .}^{\alpha}\right)$ in equation (2), if statistically significant. Positive values indicate policy hikes.

${ }^{22}$ See Annex I, Table 1 for country-by-country results. 
We combine the responses of monetary policy rates with newly estimated responses of inflation and see how those two responses change in the presence of additional policy actions such as MPMs or CFMs. To get responses of inflation, we estimate the same specification as in equation (2) replacing the dependent variable with forward inflation for each of the 20 countries in our sample:

$$
(\bar{\pi})_{t+h}^{\alpha}=\beta_{x, \pi}^{\alpha} \text { Controls }_{t}+\beta_{s, \pi}^{\alpha} \text { Shock }_{t}+\beta_{s p, \pi}^{\alpha} \text { Shock }_{t} \times \text { AddPolicy }_{t}+\varepsilon_{\pi, t+h}^{\alpha}
$$

We find that expected monetary policy actions become more sensitive to expected inflation developments when countries also use additional unconventional policies. Under these circumstances, we observe that monetary policy is more likely to tighten in the subsequent half-year if inflation is also likely to rise in the same period. Figure 13 illustrates this finding for median or "typical" responses. There, the slope of the cross-country fitted line of future inflation responses on future monetary policy actions becomes more positively sloped in the presence of additional unconventional policy actions. ${ }^{23}$ This result also holds for extreme responses to inflows and outflows. ${ }^{24}$

This evidence is suggestive that auxiliary policy actions such as MPMs and CFMs may be useful in allowing monetary policy to more squarely focus on domestic inflation objectives, regardless if "typical" and "extreme" responses are needed. These results are interesting because they highlight the dilemma behind monetary policy responses in the face of capital inflows. On the one hand, monetary policy may need to be tighter, because inflows are typically associated with inflationary pressures. On the other hand, though, policy makers may refrain from tightening policy rates because that could itself attract further inflows which would then add to the existing inflationary pressures. Our results point to the fact that additional unconventional policy tools such as MPMs and CFMs may help break this dilemma and allow monetary policy to focus on its inflation objectives, in spite of external pressures.

\footnotetext{
${ }^{23}$ Note that the difference between the cloud of points without and with additional policy tools is small and driven by a few countries, as mentioned upfront. This is because of two factors: (i) not all countries have actively used unconventional policy tools such as MPMs or CFMs; (ii) for those that have used such measures, some have estimates of the interaction terms $\beta_{s k, \pi}^{\alpha}, \beta_{s p, i}^{\alpha}$ that are not distinguishable from zero, a fact we attribute -at times - to low power, given the small number of observations, or could also reflect the lack of effectiveness of such measures.

${ }^{24}$ Extreme responses to inflows combine the $10^{\text {th }}$ percentile of responses of monetary policy rates and inflation while those to outflows combine the $90^{\text {th }}$ percentile of both.
} 
Figure 13: "Typical" Monetary and Inflation Responses with(out) Additional Tools

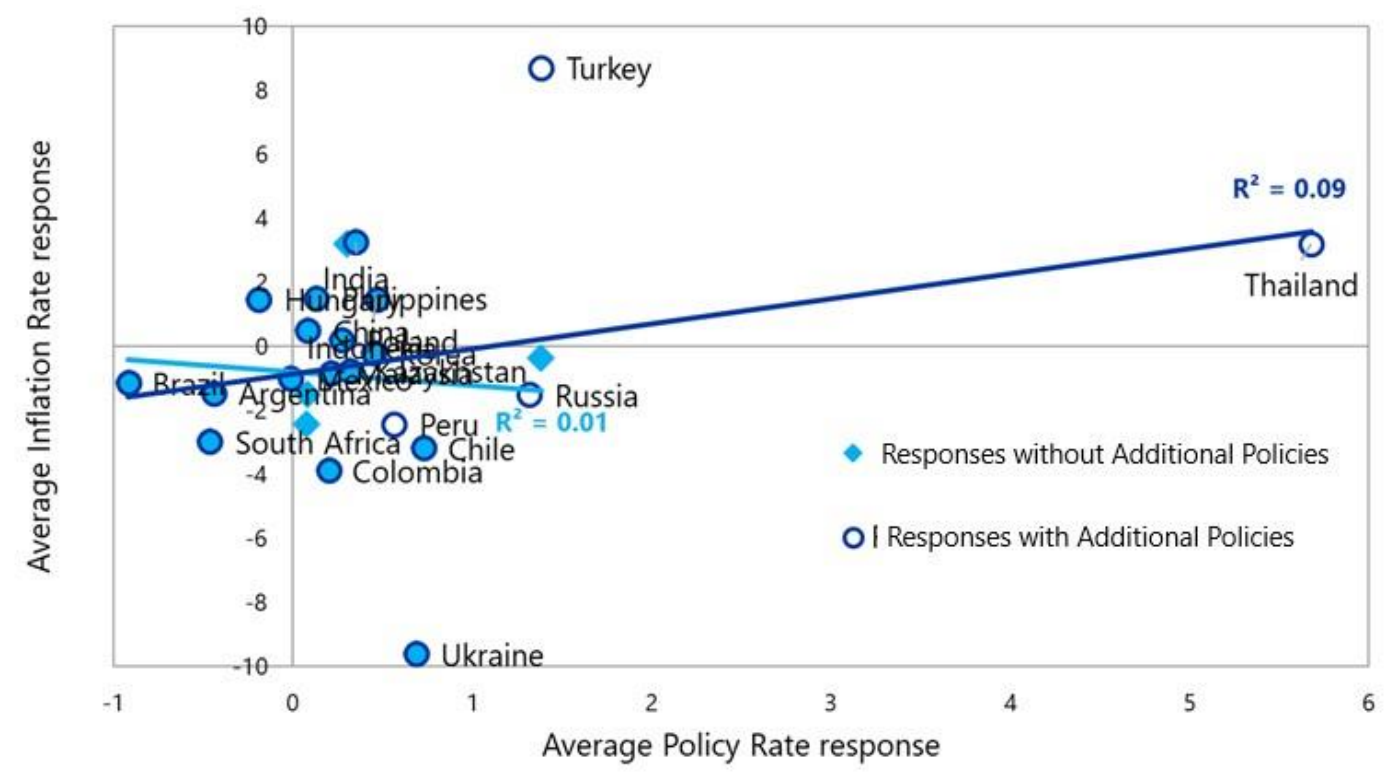

Sources: IMF Staff estimates.

Notes: The chart shows the two-quarter ahead median or "typical" response of monetary policy and inflation to a one percent exogenous flow shock. Each marker is a country, with light blue diamonds showing the relationship between monetary policy and inflation responses when ignoring the interaction term with additional policy tools, e.g., $\beta_{s, \pi}^{0.5}$ only in equation (2), while the dark blue circles represent responses when also the interaction term with additional policy tools is taken into account, e.g., $\left(\beta_{s, \pi}^{0.5}+\beta_{s p, \pi}^{0.5}\right)$ in equation (2).

\section{B. Asymmetric Impact of Additional Policies}

Our second finding is that additional policy tools such as MPMs or CFMs seem to have somewhat asymmetric impacts on FX interventions and exchange rate responses, with "extreme" FX sales or exchange rate depreciations being more affected than "extreme" FX purchases or exchange rate appreciations.

Figure 14 illustrates the asymmetry. The left panels show responses of both FX intervention and exchange rates without the use of additional policy tools such as MPMs or CFMs, while the panels on the right show responses in the presence of these measures. When facing outflows, FX sales are clearly larger when combined with the active implementation of additional policy measures. But the same pattern (with the opposite sign) is not clearly discernable when facing inflows. Similarly, exchange rates tend to appreciate more than they would otherwise when countries face outflows and deploy auxiliary unconventional policy tools, while there is no clear pattern in case of inflows pressures. Thus, countries who deploy effectively additional policy tools such as MPMs or CFMs during times of outflows tend to also combine them with supporting FX sales ${ }^{25}$, with the opposite being much less clear during times of inflows. Exchange rates tend also to respond asymmetrically.

\footnotetext{
${ }^{25}$ While the asymmetry of FXI is driven by Malaysia's responses, the asymmetry of exchange rate is broader.
} 
These results suggest that the deployment of additional policies likely reflect a concern of a few countries that resort to them about a particular state of the world, where "extreme" sales and depreciations would be the natural responses.

\section{Figure 14: Impact of Additional Policies on FXI and Exchange Rate Responses}

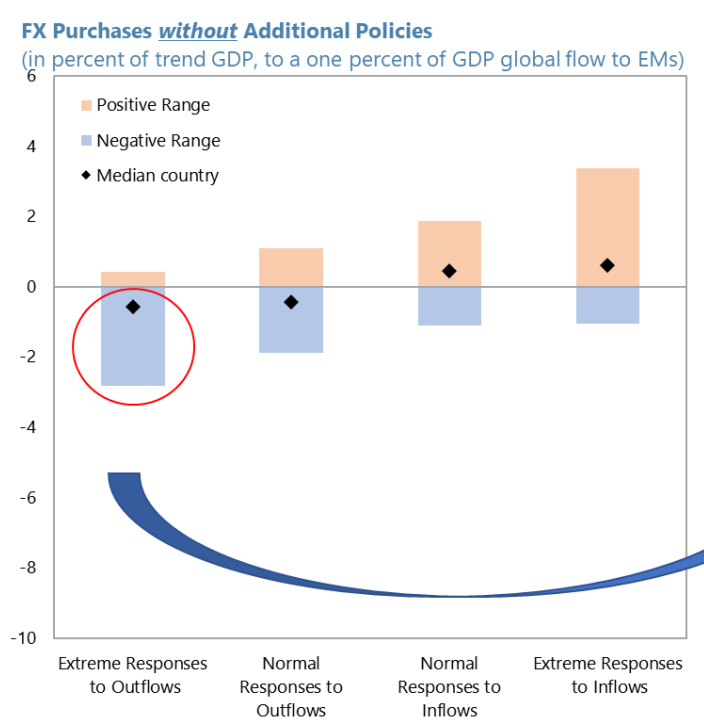

FX Purchases with Additional Policies

(in percent of trend GDP, to a one percent of GDP global flow to EMs)

(in percent, to a one percent of GDP global flow to EMs)

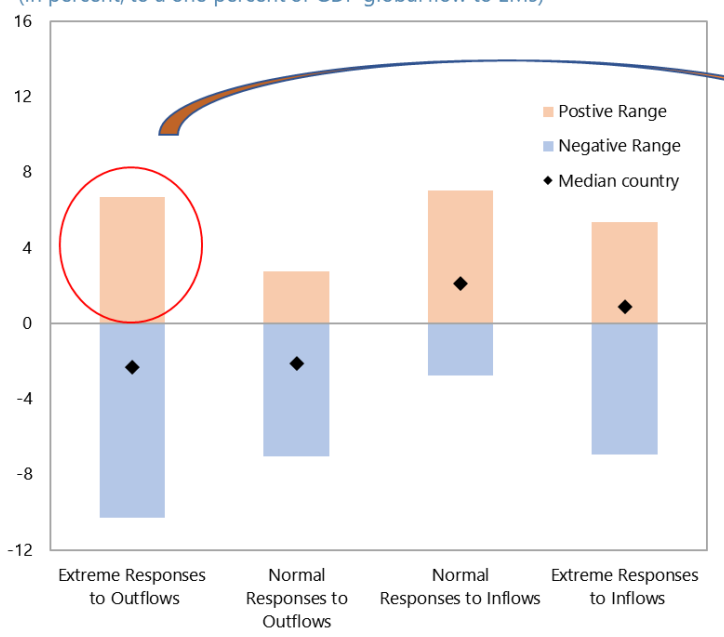


However, the impact of unconventional policy on country-specific flows does not appear to be independent by the time-horizon. To further investigate this impact, we estimate the same specification as in equation (2) replacing the dependent variable with non-resident capital inflows for each of the 20 countries in our sample:

$$
(\overline{c f})_{t+h}^{\alpha}=\beta_{x, c f}^{\alpha} \text { Controls }_{t}+\beta_{s, c f}^{\alpha} \text { Shock }_{t}+\beta_{s p, c f}^{\alpha} \text { Shock }_{t} \times \text { AddPolicy }_{t}+\varepsilon_{c f, t+h}^{\alpha}
$$

Interestingly, we find that country-specific flows seem to be more affected in the long-term compared to the short-term. Figure 15 compares the effect of additional policy tools 2quarters ahead from that 2-years ahead.

\section{Figure 15: Effects of Additional Policy Tools on Capital Flows Responses Over Time}
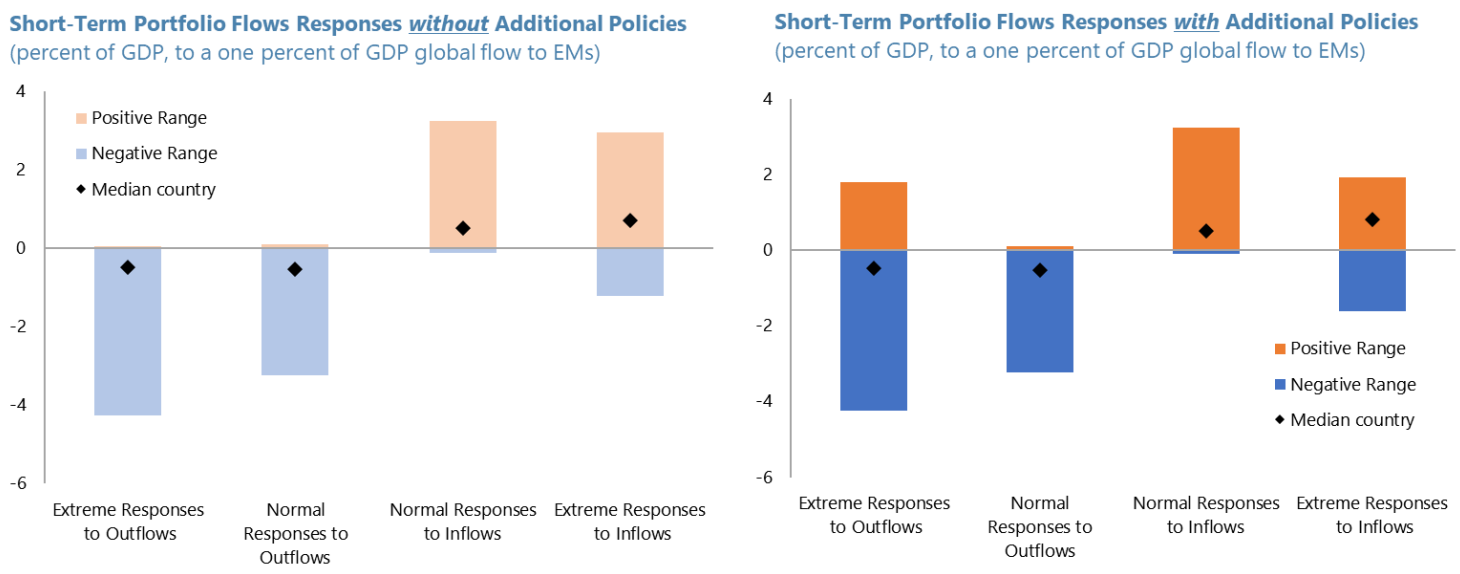

Medium-Term Portfolio Flows without Additional Policies (percentage points, to a one percent of GDP global flow to EMs)

Medium-Term Portfolio Flows with Additional Policies (percentage points, to a one percent of GDP global flow to EMs)

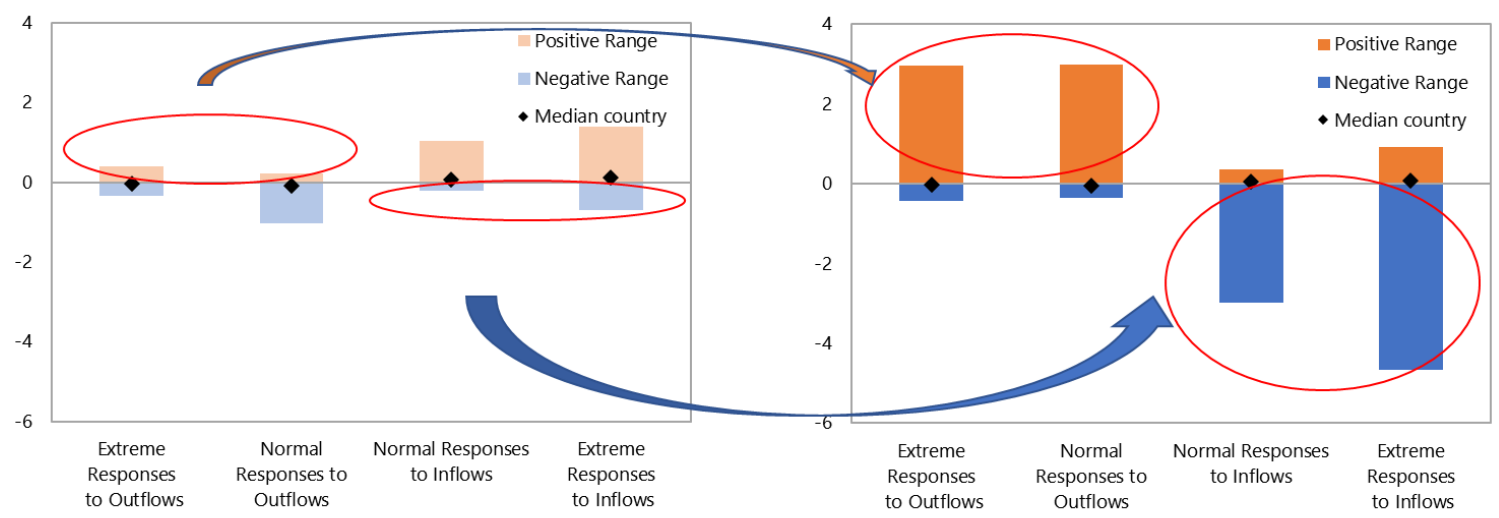

Notes: The chart shows the full range of average two-quarter ahead coefficients across countries. The chart on the left shows only unconditional coefficients, e.g. ( $\left.\beta_{s, .}^{\alpha}\right)$ in equation (2), while the chart on the right adds the interaction coefficient between the exogenous shock and the additional policy variable, e.g., $\left(\beta_{s, .}^{\alpha}+\beta_{s p, .}^{\alpha}\right)$ in equation (2), if statistically significant. The top charts show average responses at the 2-quarter ahead horizon while those in the bottom show average responses at the 2-year ahead horizon. 
While at the 2-quarter ahead horizon, auxiliary policy tools barely affect flows (comparing across charts at the top, responses seem unchanged), at the 2-year horizon these tools seem much more effective at moderating both extreme outflows and extreme inflows (comparing the charts in the bottom). These results thus indicate that additional unconventional policy tools may have the potential to improve policy trade-offs over the short-term, while impacting quantities (e.g., flows themselves) over the medium term.

\section{Conclusions}

Policymakers in EMs have increasingly faced the challenge of managing large and volatile capital flows that are often driven by external factors. Interestingly, the responses to this challenge have varied widely across countries: while some have allowed their exchange rate to be flexible and act as shock absorber, others have used policy tools such as monetary policy, FXI, MPMs and CFMs to "lean against the wind" and help smooth exchange rate volatility. Existing research, so far, does not provide guidance on how to monitor and assess the choice of a country's policy mix in the face of exogenous capital flow pressures, as the effects of many of these policies - let alone their interaction-remains under debate among both academics and policy practitioners.

In this paper, we document the cross-country variety of policy responses to external capital flow pressures for a representative sample of 20 EMs over almost two decades and investigate the rationale behind them. To do that, we estimate the whole expected distribution of future exchange rate, interest rate and FX intervention responses at any given point in time for each individual country in the sample - an exercise that is useful to think about (and assess) likely future policy moves in different EMs, given available information on global and country-specific macro-financial conditions.

Focusing on FXI, interest rate and exchange rate changes, we find that policy responses to global capital flows are indeed highly heterogeneous across countries, even after controlling for an exogenous, same-sized shock. Moreover, for most of the countries, policy responses are found to be fat-tailed - with larger "extreme" responses compared to those around the median - and asymmetric, with larger exchange rate adjustment, interest rate changes and forex intervention in response to outflows than in response to inf while still retaining evenhandedness across lows.

We also find different policy choices across countries to be linked to different countryspecific concerns. For example, estimated responses of FXI (both "typical" and "extreme") are found to be positively related to balance sheet vulnerabilities and inversely related to the depth of the forex market. While no causality relationship can be ascertained, we think this analysis contributes to narrowing the list of structural country characteristics that may either explain why certain countries respond a certain way or indicate that certain policies, if repeated often, may lead to the development of certain characteristics over time.

Finally, our findings suggest that the use of complementary policy tools such as CFMs and MPMs targeting buildup of external balance sheet vulnerabilities in the system can be useful in enhancing monetary policy autonomy: bringing these policy instruments into play appears 
to strengthen the sensitivity of both "typical" and "extreme" monetary policy responses to expected domestic cyclical developments.

Needless to say, the analysis conducted in this paper is not normative. We are silent on what countries should or could have done instead and we do not explore the cost-benefit calculation that would be needed to comprehensively address this question. For example, the use of unconventional policy tools is shown to create monetary policy space in the short term. That may appear as a free lunch. However, there could be unexplored longer-term, unintended consequences from the use of these tools that may give rise to important intertemporal policy trade-offs. Moreover, countries may use unconventional policy tools to delay warranted macro-economic adjustment, which could be suboptimal. This important analysis is left for future research.

We nonetheless hope that our descriptive analysis may spur new questions and ultimately help make progress towards giving more tailored policy advice to structurally different countries while retaining the necessary evenhandedness. 


\section{REFERENCES}

Acosta-Henao, Miguel, Laura Alfaro, and Andres Fernandez, forthcoming. "Sticky Capital Controls," mimeo.

Adrian, Tobias, Nina Boyarchenko, and Domenico Giannone, 2019, "Vulnerable Growth." American Economic Review, 109 (4): 1263-89.

Adrian, Tobias, Federico Grinberg, Nellie Liang and Sheheryar Malik, 2018. "The Term Structure of Growth-at-Risk.” IMF Working Paper 2018/180.

Ahmed, Shaghil, Zlate, Andrei, 2014, "Capital flows to emerging market economies: a brave new world?" Journal of International Money and Finance, 48, 221-248.

Alam, Zohair, Adrian Alter, Joshua Eiseman, Gaston Gelos, Heedon Kang, Machiko Narita, Erlend Nier, and N. Wang, 2019, "Digging Deeper-Evidence on the Effects of Macroprudential Policies from a New Database,” IMF Working Paper No. 19/66. International Monetary Fund.

Armas, Adrian, and Marco Vega, 2019. "Peru: Foreign Exchange Intervention under Financial Dollarization," in Foreign Exchange Intervention in Inflation Targeters in Latin America, by Werner, Alejandro, Chamon, Marcos, Hofman, David, and Nicolas Magud, eds. Washington, DC: International Monetary Fund.

Azzalini, A. and A. Capitanio, 2003, "Distributions Generated by Perturbation of Symmetry with Emphasis on a Multivariate Skew t Distribution," Journal of the Royal Statistical Society, Series B, 65, pp. 367-389.

Bianchi, Javier. 2011. "Overborrowing and systemic externalities in the business cycle." The American Economic Review, 101 (7), pp. 3400-3426.

Bank of International Settlements, 2019a, "Monetary Policy Frameworks in EMEs: Inflation Targeting, the Exchange Rate and Financial Stability," BIS Annual Report, Chapter 2.

, 2019b, "Integrated Inflation Targeting," by Pierre-Richard Agénor and Luiz

A. Pereira da Silva, eds. Basel, Bank of International Settlements.

Blanchard, Olivier, Gustavo Adler, and I. de Carvalho Filho, 2015, "Can Foreign Exchange Intervention Stem Exchange Rate Pressures from Global Capital Flow Shocks?” NBER working paper 21427.

Calvo, Guillermo, 2012, “On Capital Inflows, Liquidity and Bubbles,” mimeo.

Guillermo A. Calvo and Carmen M. Reinhart, 2002, "Fear of Floating," The Quarterly

Journal of Economics, 117 (2), pp. 379-408. 
Igan, Deniz O., Ali M. Kutan and Ali Mirzae, 2016, "Real Effects of Capital Inflows in Emerging Markets," IMF Working Papers 16/235.

Forbes, Kristin J., and Francis Warnock, 2012, "Capital Flow Waves: Surges, Stops, Flight and Retrenchment," Journal of International Economics, 88, No. 2, pp. 235-251.

Fraga, Arminio, Ilan Goldfajn and André Minella, 2004, "Inflation Targeting in Emerging Market Economies," chapter in NBER Macroeconomics Annual, 18, edited by Mark Gertler and Kenneth Rogoff.

Fratzscher, Marcel, 2012, "Capital Flows, Push Versus Pull Factors and the Global Financial Crisis," Journal of International Economics, 88, No. 2, pp. 341-56.

Furceri, Davide, Stéphanie Guichard and Elena Rusticelli, 2012, "The effect of episodes of large capital inflows on domestic credit," The North American Journal of Economics and Finance, Elsevier, vol. 23(3), pages 325-344.

Gelos, Gaston, Gornicka, Lucyna, Koepke, Robin, Sahay, Ratna, and Silvia Sgherri, forthcoming, "Capital Flows at Risk: Taming the Ebbs and Flows," IMF Working Paper. International Monetary Fund.

Ghosh, Atish R., Mahvash S. Qureshi, Jun Il Kim, and Juan Zalduendo, 2014, "Surges." Journal of International Economics 92, no. 2: 266-285.

Ghosh, Atish R., Jonathan D. Ostry, and Mahvash S. Qureshi. 2017. "Managing the Tide: How Do Emerging Markets Respond to Capital Flows?" IMF Working Paper 17/69.

Gourinchas, Pierre-Olivier, and Maurice Obstfeld, 2012, "Stories of the Twentieth Century for the Twenty-First." American Economic Journal: Macroeconomics 4 pp. 226-65.

Harrison, A., Love, I., McMillian, M., 2004, "Global capital flows and financing constraints," Journal of Development Economics, 75 (1), 269-301.

International Monetary Fund, 2012, The Liberalization and Management of Capital FlowsAn Institutional View, November 2012.

http://www.imf.org/external/np/pp/eng/2012/111412.pdf.

, 2013a, Guidance Note for the Liberalization and Management of Capital

Flows, April 2013. https://www.imf.org/external/np/pp/eng/2013/042513.pdf.

,2013b, Key Aspects of Macroprudential Policy, June 2013.

http://www.imf.org/external/np/pp/eng/2013/061013b.pdf.

, 2017, “Global Financial Stability Report.” Washington, October 2017.

, 2018, “Global Financial Stability Report.” Washington, April 2018. 
Departmental Paper

2019. "Facing the Tides: Managing Capital Flows in Asia." APD

Jeanne, Olivier, and Anton Korinek. 2019. "Managing credit booms and busts: A Pigouvian taxation approach," Journal of Monetary Economics, Vol. 107, pp. 2-17

Jordà, Òscar, 2005, "Estimation and Inference of Impulse Responses by Local Projections." American Economic Review, 95 (1): 161-182.

Korinek, Anton, 2018. "Regulating capital flows to emerging markets: An externality view," Journal of International Economics, vol. 111(C), pp. 61-80.

Korinek, Anton and Damiano Sandri, 2016. "Capital controls or macroprudential regulation?," Journal of International Economics, vol. 99(S1), pp. 27-42.

Lafarguette, R., 2019, “Growth at Risk Tool: Technical Appendix.” mimeo, International Monetary Fund.

Mendoza, Enrique, 2000, "Sudden Stops, Financial Crises, and Leverage," American Economic Review 100, pp. 1941-1966.

Menkhoff, L., 2013, "Foreign exchange intervention in emerging markets: a survey of empirical studies. World Econ. 36, 1187-1208.

Mohanty, Madhusudan and Bat-el Berger, 2013, "Central Bank Views on Foreign Exchange Intervention," in Market Volatility and Foreign Exchange Intervention: What Has Changed?, BIS Papers, no 73.

Neely, Christopher J., 2008, “Central bank authorities' beliefs about foreign exchange intervention," Journal of International Money and Finance, 27 (1), pp. 1-25.

Prasad, Ananthakrishnan, Elekdag, Selim, Jeasakul, Phakawa, Lafarguette, Romain, Alter, Adrian, Feng, Alan, Wang, Changchun, 2019. "Growth at Risk: Concept and Application in IMF Country Surveillance.” IMF Working Papers 19/36.

Tong, Hui, Wei, Shang-Jin, 2011, "The composition matters: capital inflows and liquidity crunch during a global economic crisis," Review of Financial Studies, 24, 2023-2052.

Werner, Alejandro, Chamon, Marcos, Hofman, David, and Nicolas Magud, eds. 2019. Foreign Exchange Intervention in Inflation Targeters in Latin America. Washington, DC: International Monetary Fund. 
ANNEX I - TABLES

Table 1. Quantile Regressions Estimates-2-Quarters Ahead Predictions

\begin{tabular}{|c|c|c|c|c|c|c|c|c|c|}
\hline \multirow[b]{2}{*}{ Quantile } & \multicolumn{3}{|c|}{ Exchange Rate } & \multicolumn{3}{|c|}{ Interest Rate } & \multicolumn{3}{|c|}{$F X I$} \\
\hline & 0.1 & 0.5 & 0.9 & 0.1 & 0.5 & 0.9 & 0.1 & 0.5 & 0.9 \\
\hline \multicolumn{10}{|l|}{ Argentina } \\
\hline Shock & 0.17 & -2.17 & -1.23 & -0.03 & -0.44 & -5.53 & 2.13 & 0.30 & 0.25 \\
\hline Shock*AddPolicy & -0.10 & -3.51 & 7.46 & -0.45 & -0.14 & 2.92 & 0.76 & 1.23 & 1.92 \\
\hline \multicolumn{10}{|l|}{ Brazil } \\
\hline Shock & -4.64 & -7.16 & -10.41 & 0.41 & -0.92 & 0.00 & 0.32 & 1.14 & 1.27 \\
\hline Shock*AddPolicy & -1.44 & 3.69 & 8.85 & 0.12 & -0.52 & 0.37 & -0.83 & -0.82 & -1.14 \\
\hline \multicolumn{10}{|l|}{ Chile } \\
\hline Shock & -1.38 & -1.45 & -4.07 & 1.82 & 0.73 & 0.41 & -0.26 & -0.11 & -1.11 \\
\hline Shock*AddPolicy & 0.00 & 0.00 & 0.00 & 0.00 & 0.00 & 0.00 & 0.00 & 0.00 & 0.00 \\
\hline \multicolumn{10}{|l|}{ China } \\
\hline Shock & 0.72 & -0.13 & 0.79 & 0.37 & 0.08 & 0.12 & 0.19 & 0.82 & 1.66 \\
\hline Shock*AddPolicy & 3.46 & 0.80 & 4.36 & 0.60 & 0.06 & -0.06 & 1.62 & -0.21 & -0.81 \\
\hline \multicolumn{10}{|l|}{ Colombia } \\
\hline Shock & -5.42 & -2.66 & -6.33 & 1.21 & 0.20 & -0.35 & 0.20 & 0.38 & 0.56 \\
\hline Shock*AddPolicy & 0.00 & 0.00 & 0.00 & 0.00 & 0.00 & 0.00 & 0.00 & 0.00 & 0.00 \\
\hline \multicolumn{10}{|l|}{ Hungary } \\
\hline Shock & -0.97 & -0.41 & -2.51 & 0.44 & -0.19 & -0.07 & -0.15 & -0.34 & 0.00 \\
\hline Shock*AddPolicy & -3.26 & 3.34 & 8.15 & -2.53 & -0.74 & 0.36 & -1.24 & 1.34 & 4.35 \\
\hline \multicolumn{10}{|l|}{ Indonesia } \\
\hline Shock & -1.88 & 0.26 & -0.59 & 0.88 & 0.46 & 0.76 & -0.07 & 0.30 & 1.11 \\
\hline Shock*AddPolicy & -1.00 & -2.82 & -0.25 & -0.11 & 0.10 & -0.23 & 0.52 & 0.34 & -0.03 \\
\hline \multicolumn{10}{|l|}{ India } \\
\hline Shock & -1.99 & -0.57 & -0.77 & 0.81 & 0.35 & 0.41 & 0.52 & 0.13 & 0.37 \\
\hline Shock*AddPolicy & -0.37 & -1.81 & -3.39 & 0.63 & 0.06 & 0.15 & 0.17 & 0.62 & 1.54 \\
\hline \multicolumn{10}{|l|}{ Kazakstan } \\
\hline Shock & 7.13 & 2.90 & 7.00 & 0.41 & 0.32 & -1.50 & -0.43 & 0.39 & 1.23 \\
\hline Shock*AddPolicy & 0.00 & 0.00 & 0.00 & 0.00 & 0.00 & 0.00 & 0.00 & 0.00 & 0.00 \\
\hline Korea & & & & & & & & & \\
\hline Shock & 0.10 & -2.51 & -1.25 & 0.54 & 0.45 & 0.31 & 0.62 & 0.50 & 0.63 \\
\hline Shock*AddPolicy & -7.87 & -1.42 & -2.07 & -0.39 & -0.18 & 0.12 & 0.41 & -0.09 & 2.64 \\
\hline Mexico & & & & & & & & & \\
\hline Shock & -0.84 & -4.82 & -5.75 & 0.88 & -0.01 & -0.42 & 0.73 & 0.62 & 0.63 \\
\hline Shock*AddPolicy & 0.00 & 0.00 & 0.00 & 0.00 & 0.00 & 0.00 & 0.00 & 0.00 & 0.00 \\
\hline Malaysia & & & & & & & & & \\
\hline Shock & -0.61 & -2.06 & -2.16 & 0.53 & 0.21 & 0.24 & 2.15 & 1.79 & 3.43 \\
\hline Shock*AddPolicy & 5.26 & 2.71 & -0.18 & 0.13 & -0.10 & -0.55 & 7.23 & -0.59 & -7.33 \\
\hline Philippines & & & & & & & & & \\
\hline Shock & -2.18 & -2.41 & -1.75 & 0.39 & 0.13 & -0.16 & 2.82 & 1.68 & 2.54 \\
\hline Shock*AddPolicy & 0.00 & 0.00 & 0.00 & 0.00 & 0.00 & 0.00 & 0.00 & 0.00 & 0.00 \\
\hline Peru & & & & & & & & & \\
\hline Shock & 0.88 & 0.48 & 1.07 & 1.23 & 0.07 & 0.22 & 1.73 & 1.89 & 2.18 \\
\hline Shock*AddPolicy & 0.49 & -0.09 & 0.30 & -0.16 & 0.49 & 0.64 & 0.33 & 0.03 & 0.23 \\
\hline Poland & & & & & & & & & \\
\hline Shock & -0.96 & -3.21 & -4.08 & 0.89 & 0.27 & 0.26 & 0.89 & 0.80 & 0.23 \\
\hline Shock*AddPolicy & 3.45 & 4.32 & 0.01 & 0.31 & -0.24 & -0.15 & 0.70 & 0.90 & -0.53 \\
\hline Russia & & & & & & & & & \\
\hline Shock & -0.31 & -2.70 & -5.50 & -0.14 & 0.08 & 1.16 & 1.96 & 0.35 & 0.90 \\
\hline Shock*AddPolicy & -2.46 & -2.38 & 0.31 & 1.29 & 1.24 & 2.51 & -1.35 & -3.53 & -1.44 \\
\hline Thailand & & & & & & & & & \\
\hline Shock & -1.14 & -0.94 & 0.02 & 0.68 & 0.30 & 0.57 & 1.41 & 0.68 & 0.42 \\
\hline Shock*AddPolicy & 8.69 & 11.00 & 14.74 & 5.21 & 5.38 & 6.89 & 5.79 & 3.05 & -0.77 \\
\hline Turkey & & & & & & & & & \\
\hline Shock & -2.63 & -3.31 & -6.36 & 2.91 & 1.38 & -0.33 & -0.01 & 0.60 & 0.33 \\
\hline Shock*AddPolicy & -6.06 & -3.87 & 4.10 & -4.35 & 0.71 & 4.65 & -0.28 & 0.03 & 1.26 \\
\hline Ukraine & & & & & & & & & \\
\hline Shock & 1.11 & -0.77 & -7.62 & 0.61 & 0.69 & 1.75 & 2.52 & -1.15 & 0.52 \\
\hline Shock*AddPolicy & 0.23 & 0.08 & 1.66 & -0.57 & 1.07 & 0.37 & 0.71 & -0.38 & -0.84 \\
\hline South Africa & & & & & & & & & \\
\hline Shock & 3.51 & -4.68 & -4.26 & 0.91 & -0.47 & -0.19 & 0.11 & 0.25 & 0.71 \\
\hline Shock*AddPolicy & 0.00 & 0.00 & 0.00 & 0.00 & 0.00 & 0.00 & 0.00 & 0.00 & 0.00 \\
\hline
\end{tabular}

Note: Bold font indicates significance at 10 percent. The additional policy variable AddPolicy is also included as a standalone control in each of the regressions. Comprehensive results and goodness of fit statistics are available upon request. 
Table 2. Quantile Regressions Estimates-2-Years Ahead Predictions

\begin{tabular}{|c|c|c|c|c|c|c|c|c|c|}
\hline \multirow[b]{2}{*}{ Quantile } & \multicolumn{3}{|c|}{ Exchange Rate } & \multicolumn{3}{|c|}{ Interest Rate } & \multicolumn{3}{|c|}{$F X I$} \\
\hline & 0.1 & 0.5 & 0.9 & 0.1 & 0.5 & 0.9 & 0.1 & 0.5 & 0.9 \\
\hline \multicolumn{10}{|l|}{ Argentina } \\
\hline Shock & -2.35 & -0.60 & -7.51 & -0.03 & -0.44 & -5.53 & 0.92 & 0.00 & 0.53 \\
\hline Shock*AddPolicy & -1.76 & -2.52 & 2.51 & -0.45 & -0.14 & 2.92 & 1.48 & 0.77 & 1.75 \\
\hline \multicolumn{10}{|l|}{ Brazil } \\
\hline Shock & 1.02 & -1.12 & -5.57 & 0.41 & -0.92 & 0.00 & -0.14 & 1.14 & 0.23 \\
\hline Shock*AddPolicy & -1.69 & 2.19 & 4.22 & 0.12 & -0.52 & 0.37 & 0.27 & -0.96 & 0.33 \\
\hline \multicolumn{10}{|l|}{ Chile } \\
\hline Shock & 0.35 & -0.02 & -0.71 & 1.82 & 0.73 & 0.41 & 0.28 & -0.01 & 0.46 \\
\hline Shock*AddPolicy & 0.00 & 0.00 & 0.00 & 0.00 & 0.00 & 0.00 & 0.00 & 0.00 & 0.00 \\
\hline \multicolumn{10}{|l|}{ China } \\
\hline Shock & -0.87 & -0.30 & 0.05 & 0.37 & 0.08 & 0.12 & 0.03 & 0.11 & -0.05 \\
\hline Shock*AddPolicy & -0.55 & 0.10 & 7.76 & 0.60 & 0.06 & -0.06 & 1.61 & 0.05 & -0.43 \\
\hline \multicolumn{10}{|l|}{ Colombia } \\
\hline Shock & -1.25 & -0.98 & -4.93 & 1.21 & 0.20 & -0.35 & 0.09 & 0.22 & 0.21 \\
\hline Shock*AddPolicy & 0.00 & 0.00 & 0.00 & 0.00 & 0.00 & 0.00 & 0.00 & 0.00 & 0.00 \\
\hline \multicolumn{10}{|l|}{ Hungary } \\
\hline Shock & 1.88 & 0.40 & -0.55 & 0.44 & -0.19 & -0.07 & -0.58 & -0.28 & -0.17 \\
\hline Shock*AddPolicy & -1.19 & 1.01 & 3.40 & -2.53 & -0.74 & 0.36 & -0.92 & 0.32 & 1.77 \\
\hline \multicolumn{10}{|l|}{ Indonesia } \\
\hline Shock & -0.31 & 0.80 & 1.85 & 0.88 & 0.46 & 0.76 & 0.11 & 0.05 & 0.28 \\
\hline Shock*AddPolicy & 0.01 & -0.83 & -0.97 & -0.11 & 0.10 & -0.23 & -0.21 & -0.25 & -0.28 \\
\hline \multicolumn{10}{|l|}{ India } \\
\hline Shock & -0.31 & 0.67 & 1.19 & 0.81 & 0.35 & 0.41 & -0.13 & -0.21 & -0.49 \\
\hline Shock*AddPolicy & 0.17 & 0.41 & 0.16 & 0.63 & 0.06 & 0.15 & 0.55 & -0.15 & -0.38 \\
\hline \multicolumn{10}{|l|}{ Kazakstan } \\
\hline Shock & 0.17 & 1.65 & 5.07 & 0.41 & 0.32 & -1.50 & -0.07 & -0.70 & -0.05 \\
\hline Shock*AddPolicy & 0.00 & 0.00 & 0.00 & 0.00 & 0.00 & 0.00 & 0.00 & 0.00 & 0.00 \\
\hline Korea & & & & & & & & & \\
\hline Shock & -0.20 & -0.30 & 2.30 & 0.54 & 0.45 & 0.31 & -0.70 & -0.43 & -1.32 \\
\hline Shock*AddPolicy & -3.30 & 0.37 & -3.89 & -0.39 & -0.18 & 0.12 & 0.59 & 0.19 & 1.83 \\
\hline Mexico & & & & & & & & & \\
\hline Shock & 0.18 & -0.73 & -0.71 & 0.88 & -0.01 & -0.42 & 0.05 & 0.14 & 0.25 \\
\hline Shock*AddPolicy & 0.00 & 0.00 & 0.00 & 0.00 & 0.00 & 0.00 & 0.00 & 0.00 & 0.00 \\
\hline Malaysia & & & & & & & & & \\
\hline Shock & -0.31 & -0.28 & -1.22 & 0.53 & 0.21 & 0.24 & 2.16 & 1.67 & -0.03 \\
\hline Shock*AddPolicy & 2.54 & 0.68 & -0.91 & 0.13 & -0.10 & -0.55 & -0.29 & -3.31 & -8.33 \\
\hline Philippines & & & & & & & & & \\
\hline Shock & -1.02 & -1.83 & -2.19 & 0.39 & 0.13 & -0.16 & 0.96 & 0.87 & 0.56 \\
\hline Shock*AddPolicy & 0.00 & 0.00 & 0.00 & 0.00 & 0.00 & 0.00 & 0.00 & 0.00 & 0.00 \\
\hline Peru & & & & & & & & & \\
\hline Shock & -0.09 & 0.10 & 0.20 & 1.23 & 0.07 & 0.22 & 1.37 & 0.93 & 1.00 \\
\hline Shock*AddPolicy & 0.02 & -0.24 & -0.45 & -0.16 & 0.49 & 0.64 & 2.31 & -0.01 & 0.31 \\
\hline Poland & & & & & & & & & \\
\hline Shock & -1.55 & -0.51 & -1.50 & 0.89 & 0.27 & 0.26 & 0.05 & 0.12 & 0.08 \\
\hline Shock*AddPolicy & 1.02 & 2.04 & 1.71 & 0.31 & -0.24 & -0.15 & -0.21 & 0.05 & 0.20 \\
\hline Russia & & & & & & & & & \\
\hline Shock & 0.70 & 0.15 & -1.27 & -0.14 & 0.08 & 1.16 & 0.93 & -0.54 & -0.37 \\
\hline Shock*AddPolicy & 1.00 & 2.70 & -4.55 & 1.29 & 1.24 & 2.51 & 0.56 & -2.71 & -0.36 \\
\hline Thailand & & & & & & & & & \\
\hline Shock & -0.01 & -0.06 & 0.44 & 0.68 & 0.30 & 0.57 & 0.18 & 0.24 & -0.57 \\
\hline Shock*AddPolicy & -1.51 & 1.86 & 3.88 & 5.21 & 5.38 & 6.89 & -2.65 & -2.67 & -1.17 \\
\hline Turkey & & & & & & & & & \\
\hline Shock & 0.11 & -0.72 & 2.31 & 2.91 & 1.38 & -0.33 & -0.37 & 0.06 & 0.41 \\
\hline Shock*AddPolicy & -3.26 & 0.21 & 5.62 & -4.35 & 0.71 & 4.65 & -0.65 & -0.26 & 0.54 \\
\hline Ukraine & & & & & & & & & \\
\hline Shock & 0.74 & 1.73 & -0.32 & 0.61 & 0.69 & 1.75 & 0.30 & -1.78 & -1.25 \\
\hline Shock*AddPolicy & -2.49 & -1.87 & -0.13 & -0.57 & 1.07 & 0.37 & 0.37 & 0.55 & -0.47 \\
\hline South Africa & & & & & & & & & \\
\hline Shock & 4.18 & 3.59 & -0.38 & 0.91 & -0.47 & -0.19 & -0.04 & -0.06 & -0.02 \\
\hline Shock*AddPolicy & 0.00 & 0.00 & 0.00 & 0.00 & 0.00 & 0.00 & 0.00 & 0.00 & 0.00 \\
\hline
\end{tabular}

Note: Bold font indicates significance at 10 percent. The additional policy variable AddPolicy is also included as a standalone control in each of the regressions. Comprehensive results and goodness of fit statistics are available upon request. 


\section{ANNEX II - DATA}

\section{A. Data used in quantile local projections, equation (2)}

Countries: Argentina, Brazil, Chile, China, Colombia, Hungary, India, Indonesia, Kazakhstan, Korea, Malaysia, Mexico, Peru, Philippines, Poland, Russia, South Africa, Thailand, Turkey, Ukraine.

\section{Capital flow shock $\left(\right.$ Shock $\left._{t}\right)$}

In our analysis we focus on gross portfolio inflows to EMs, i.e., net non-resident purchases of EM assets. We use quarterly balance of payments data from 1995Q1 to 2018Q3 for 20 emerging markets, based on the IMF's Financial Flow Analytics database. Gross inflows data are measured in US dollars and scaled by annual HP-filtered GDP sourced from the IMF's World Economic Outlook dataset. The shock is constructed as described in the sub-section II.B.

\section{Policy responses.}

FX intervention. We estimate foreign exchange intervention by taking the balance of payments reserve flow in each quarter from the IMF's World Economic Outlook dataset and correcting it with estimates of income accrued to previous positions using information from the IMF's Currency Composition of Foreign Exchange Reserves (COFER) database. This information pertains to the currency and maturity composition of reserves, complemented with data on long-term and short-term yields of the various reserve currencies. This estimate is then normalized using annual HPfiltered GDP. A positive value means an increase in FX assets (an FX purchase), and a negative value - a decline in FX assets (an FX sale). Our estimates track well published FX intervention for countries that do so (see Annex III.B).

Policy interest rate. End-of-quarter domestic policy rates (nominal, percentage points) are taken from Haver Analytics dataset.

Exchange rate. End-of-quarter effective nominal exchange rates are taken from Haver Analytics dataset.

\section{Additional Policies:}

CFMs are taken from IMF's 2019 Taxonomy of Capital Flow Management Measures.

MPMs are taken from the IMF's Macroprudential Policy Survey database (iMaPP) as described in Alam et al. (2019).

Controls (Controls Co-1 $_{t-1}$ Growth rate of real GDP is taken from the IMF's World Economic Outlook database. 
Ratio of short-term foreign currency debt to forex reserves. Data on foreign reserves and short-term debt in foreign currency are taken from the IMF's Assessing Reserve Adequacy (ARA) database.

International commodity price index is taken from Haver Analytics dataset. Additional Policies as above.

\section{B. List of Country Characteristics}

- $\quad$ Portfolio investment assets, liabilities and assets to liabilities, Net International Investment Position Accounts, World Economic Outlook dataset.

- $\quad$ Trade openness is the sum of the country's nominal import and export as a share of nominal domestic GDP, taken from the IMF's World Economic Outlook.

- $\quad$ Capital openness is measured by the Chinn-Ito Index, computed using the IMF's Annual Report on Exchange Arrangements and Exchange Restrictions (AREAER) database.

- $\quad$ Financial Market development index, "Rethinking Financial Deepening: Stability and Growth in Emerging Markets" SDN 2015 MCM/SPR. "To overcome the shortcomings of single indicators as proxies for financial development, a new comprehensive index, capturing both financial institutions (FI) and markets (FM), is constructed. Financial institutions include banks, insurance companies, mutual funds, pension funds, and other types of nonbank financial institutions. Financial markets include mainly stock and bond markets. Within FI and FM, different dimensions of the financial system were measured: depth, access, and efficiency “

- $\quad$ FX market depth is measured by the average daily turnover in FX derivatives market, defined as the gross value of all new deals entered into during a given period, and is measured in terms of the nominal or notional amount of the contracts; based on averages across different vintages of the Triennial Central Bank Survey of Foreign Exchange and OTC Derivatives Markets.

- Short-term debt in foreign currency as percent of the stock of forex reserves. Data on forex reserves in USD and external debt in foreign currency are taken from the IMF's Assessing Reserve Adequacy (ARA) database and the World Bank's Quarterly External Debt Statistics database. Also, forex reserves in percent of ARA metric are taken from the IMF's Assessing Reserve Adequacy (ARA) database.

- Net open position in foreign exchange to capital of domestic banking sector, Financial Soundness Indicators and the IMF, Last Updated: September 2018, Core FSIs for Deposit Takers.

- $\quad$ REER overvaluation is estimated as a residual from fitting a trend through the data. 
- De facto Exchange rate Flexibility is taken from the Annual Report on Exchange Arrangements and Exchange Restrictions. The classification is based on available information on members' de facto arrangements, as analyzed by IMF staff.

- $\quad$ USD invoicing, see

https://scholar.harvard.edu/files/gopinath/files/data_invoice_currencies.xlsx from Gopinath, Gita. 2016, "The International Price System.” Jackson Hole Symposium Proceedings. NBER Digest.

- $\quad$ Several variables are normalized by nominal USD GDP, sourced from World Economic Outlook dataset, others normalized by reserves, sourced from IMF's Assessing Reserve Adequacy (ARA) database. 


\section{ANNEX III - ROBUSTNESS/CAVEATS}

\section{A. Bilateral vs Effective Exchange Rates}

In equation (2) and throughout the paper, we explored responses of effective exchange rate changes. In this sub-section we discuss how results change if looking at bilateral exchange rate changes.

Figure AIII.1 shows the average two-quarter ahead extreme responses of bilateral and effective exchange rates. The two panels show the two extreme tails $\left(10^{\text {th }}\right.$ and $90^{\text {th }}$ percentile, from left to right respectively) of exchange rate changes comparing both measures.

\section{Figure AIII.1. Exchange Rate Responses: Bilateral vs. Effective}
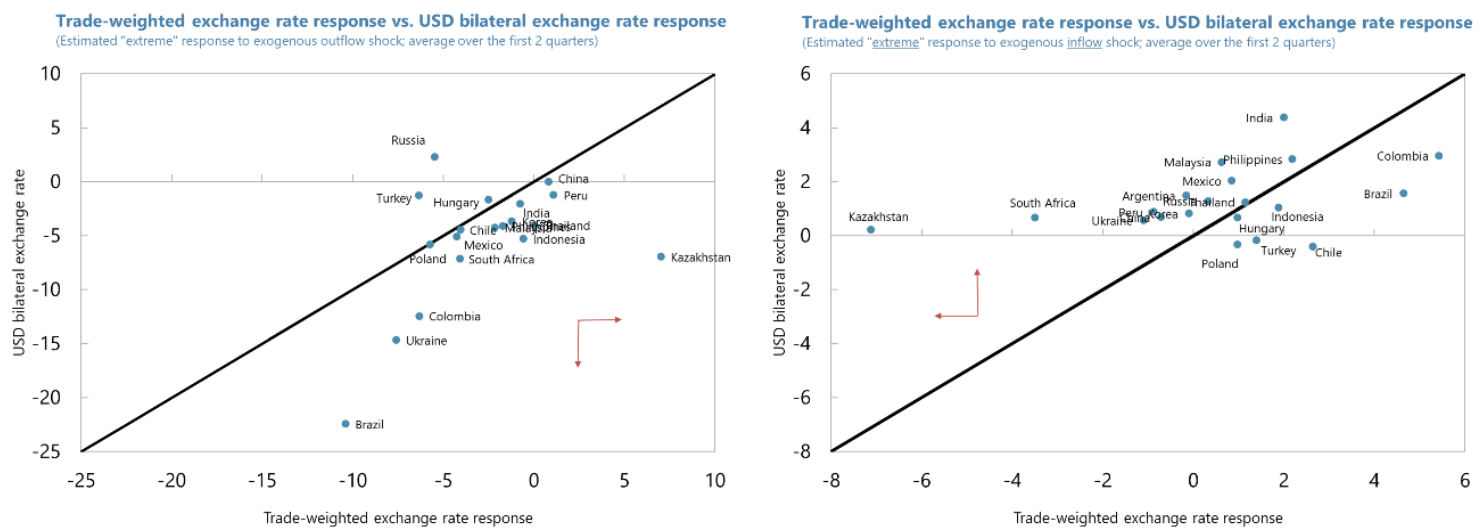

Source: IMF Staff Estimates.

Notes: The charts compare bilateral vs effective exchange rate average 2-quarter ahead responses for extreme depreciations on the left $\left(10^{\text {th }}\right.$ percentile of the distribution) and extreme appreciations on the right $\left(90^{\text {th }}\right.$ percentile).

We find that the bilateral exchange rate vis-à-vis the USD tends to be more responsive in either of the two tails, i.e. both in the case of inflow and outflow shocks. This relates to the fact that other major economies' currencies offset some of the USD movements.

\section{B. FXI Measure}

Throughout the paper, we use estimates of FX intervention rather than published intervention data. This is done because a significant number of central banks in our sample do not publish any information on their FX operations. Even those that do it, may publish it infrequently, at a too aggregated level, or may not go back enough in time. Another drawback with using published interventions data is that the definitions and coverage are not necessarily consistent across countries. To ensure cross-country consistency, we have decided to rely only on estimated FXI data rather than mixing published and estimated information. Our estimates of FXI are based on BOP data, after adjusting official foreign exchange reserve flows for interest receipts. 
In figure AIII. 2 we compare our estimates with published data on forex intervention for those countries in our sample that publish intervention data (e.g., Argentina, Brazil, Colombia, India, Mexico, Peru, Kazakhstan, Russia and Turkey).

In most cases, estimated spot interventions track very closely published FXI while non-spot interventions do not. This is to be expected since they are typically not included in published numbers. The two exceptions are Mexico and Turkey, where discrepancies likely arise from differences in the definition of FX interventions across published and estimated series.

This comparison gives us some confidence that our estimates are reasonably close to actuals.

Figure AIII.2. Published and Estimated FX intervention
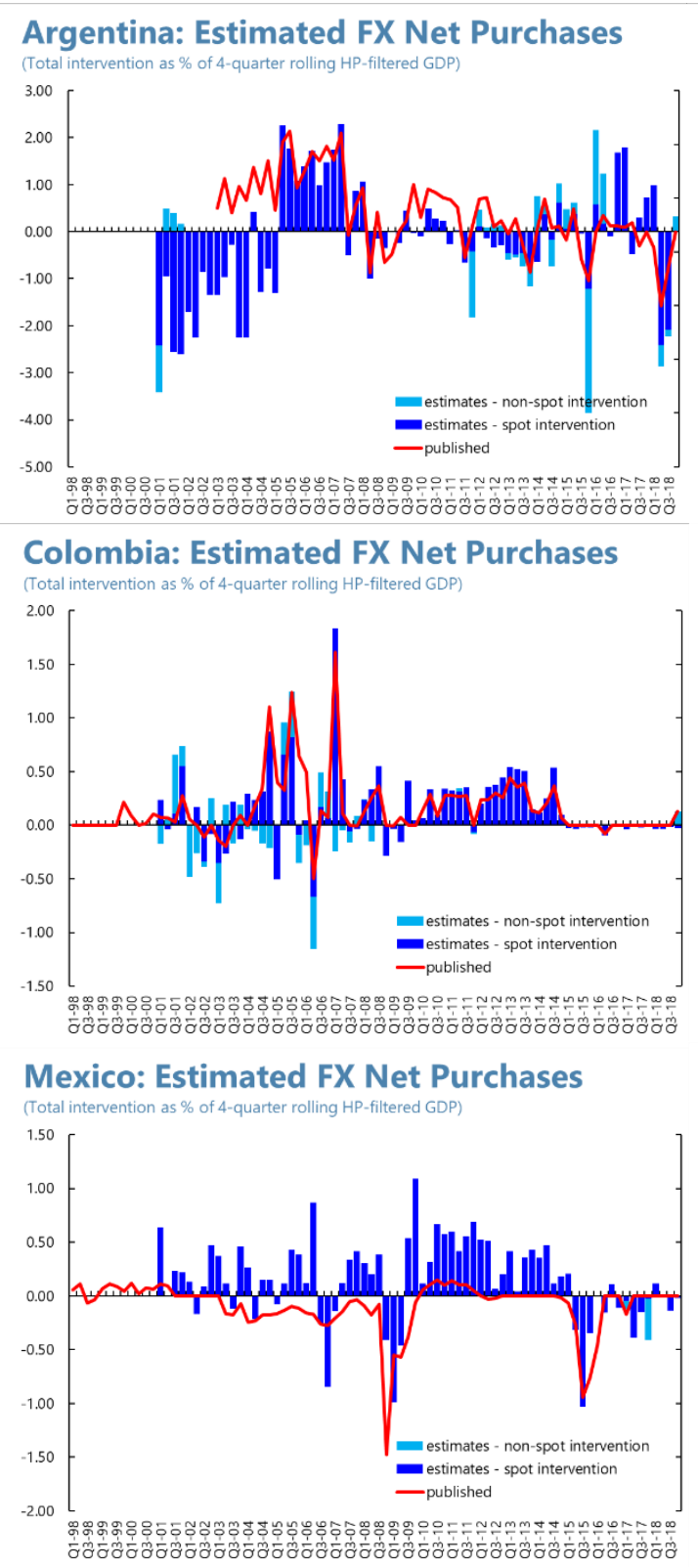

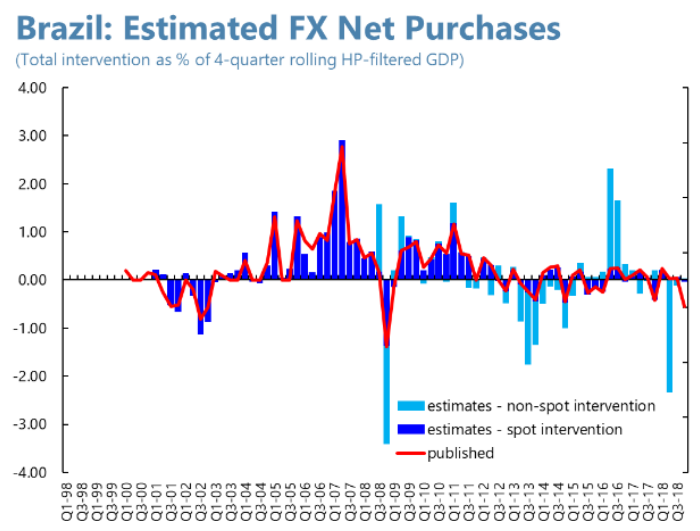

India: Estimated FX Net Purchases

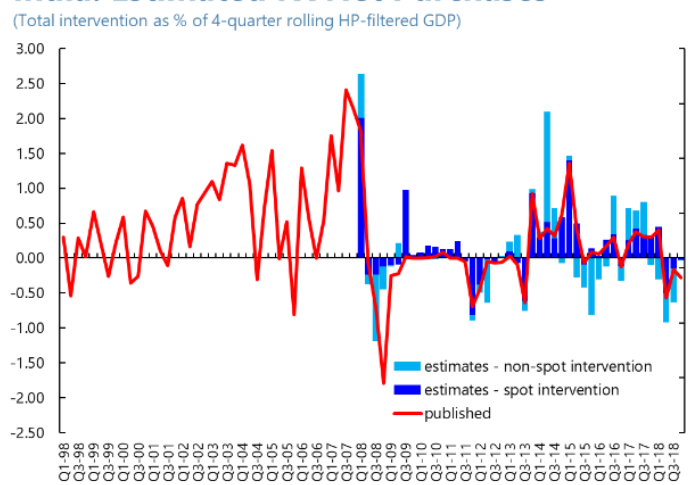

Peru: Estimated FX Net Purchases

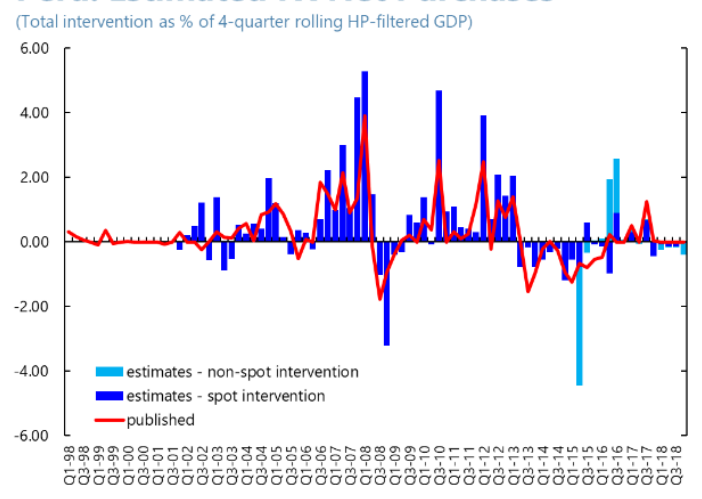


Kazakhstan: Estimated FX Net Purchases

(Total intervention as \% of 4-quarter rolling HP-filtered GDP)

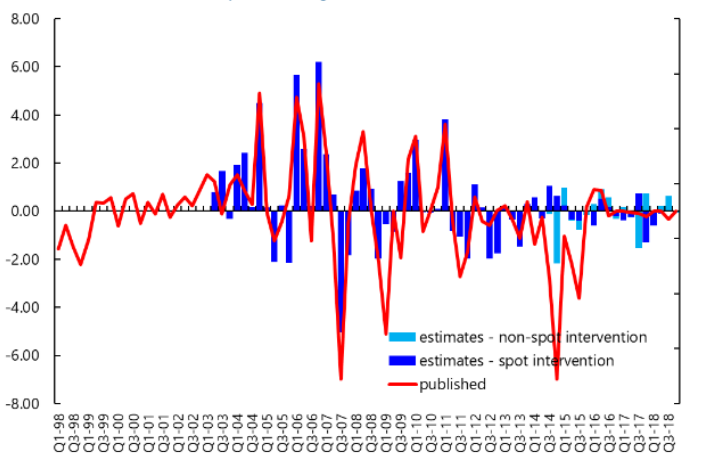

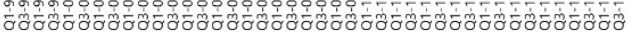

Turkey: Estimated FX Net Purchases

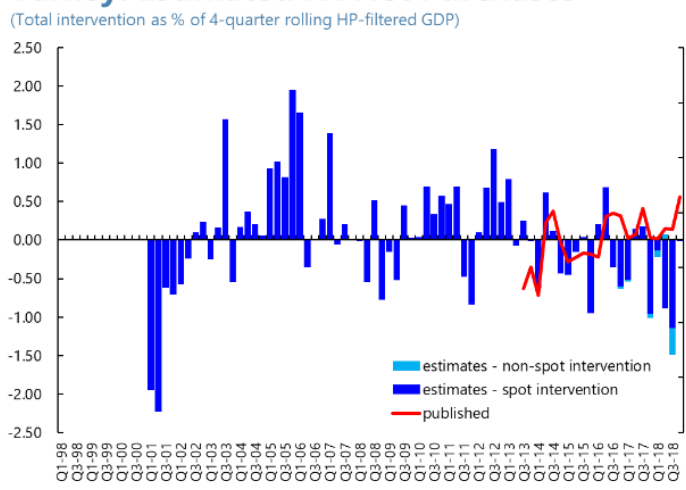

Russia: Estimated FX Net Purchases

(Total intervention as \% of 4 -quarter rolling HP-filtered GDP)

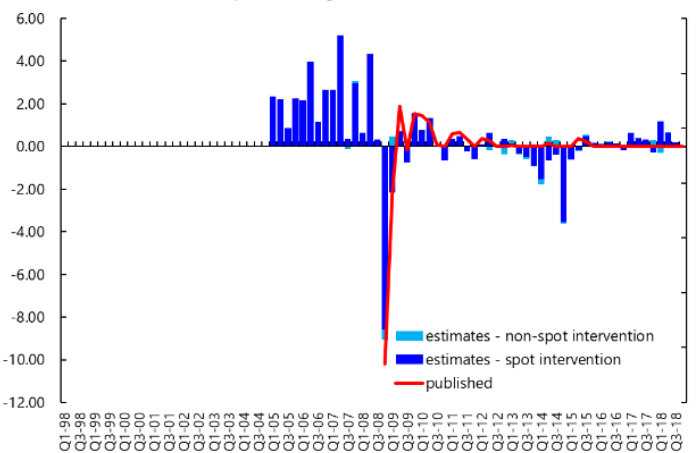

Source: Websites of various Central Banks, IMF Staff Estimates.

Notes: The charts compare our proxy for FX intervention, broken down by spot and forward interventions (dark and light blue bars, respectively), and published FX intervention (red line). 